\title{
Examining the Predictability of the Successive MJO Events of November 2011 Using Coupled 30-Day NAVGEM and COAMPS Simulations
}

\author{
William A. Komaromi, Xiaodong Hong, Matthew A. Janiga, Carolyn A. Reynolds, \\ JAMES A. Ridout, AND JAMES D. DOYLE \\ Naval Research Laboratory, Monterey, California
}

(Manuscript received 21 September 2018, in final form 11 March 2019)

\begin{abstract}
Given the prohibitive expense of running a global coupled high-resolution model for multiweek forecasts, we explore the feasibility of running a limited-area model forced by a global model on monthly time scales. Specifically, we seek to understand the constraints of the accuracy of lateral boundary conditions (LBCs) produced by NAVGEM on the skill of limited-area COAMPS forecasts. In this study, we analyze simulations of the successive MJO events of November 2011. In the NAVGEM simulations, the effect of ocean boundary conditions are examined, including fixed sea surface temperature (SST), observed SST, and coupled SST with HYCOM. With fixed SST, the second MJO fails to develop, highlighting the importance of the ocean response in the ability to model successive MJO events. Next, we examine the dependence of the regional COAMPS skill on the global model forecast performance. It is found that even when using the inferior but computationally inexpensive uncoupled NAVGEM for LBCs, coupled COAMPS can accurately predict the successive MJO events. A well-resolved atmospheric Rossby wave that slowly propagates westward in the COAMPS domain contributes to increased predictive skill. Ocean coupling and the ability of the model to sufficiently warm the ocean during the convectively suppressed phase also appears to be critical. Last, while COAMPS exhibits a significant moist bias, the sign and magnitude of the vertical and horizontal moisture flux appear to be consistent with reanalysis, a necessary attribute of any model to be used in multiweek MJO prediction.
\end{abstract}

\section{Introduction}

The Madden-Julian oscillation (MJO) is the dominant mode of variability over the Indian Ocean and Maritime Continent on the 30-60-day time scale (Madden and Julian 1971, 1972; Zhang 2005). The MJO also projects onto global temperature and precipitation patterns (see Zhang (2013) for a review), as well as global tropical cyclone activity (Klotzbach 2010, 2014) via teleconnections. Moreover, case studies indicate that the predictability time scale for extended-range forecasts can vary tremendously based on the state of the MJO (Xiang et al. 2015). Therefore, advancements in our ability to predict the MJO on multiweek time scales are critical for improving subseasonal forecasts worldwide.

MJO events tend to be preceded by a convectively suppressed phase associated with anomalously dry

Corresponding author: William A. Komaromi, will.komaromi@ nrlmry.navy.mil conditions throughout the depth of the troposphere. During the suppressed phase, a lack of cloud cover leads to enhanced warming of the ocean surface via increased shortwave radiation and the buildup of diurnal warm layers, while weaker surface winds reduce ocean cooling due to latent and sensible heat fluxes (Weller and Anderson 1996; Shinoda and Hendon 1998; Bellenger and Duvel 2009). The atmosphere then rapidly moistens as the MJO initiates (Chen et al. 2015). Capturing this transition from net heat flux into the ocean during the suppressed phase, to net heat flux from the ocean to the atmosphere is important in order to capture the intensity and propagation of the MJO (Stephens et al. 2004; DeMott et al. 2015). While perhaps not explicitly stated in the literature, our interpretation of past studies (e.g., Fu et al. 2015; Tseng et al. 2015; Hung and Sui 2018) is that it is necessary for a convectively suppressed phase and a remoistening phase to follow an initial MJO event in order for a successive MJO to occur. Matthews (2008) attributes the initiation of the successive MJO event to 
the arrival of the globally circumnavigating signal associated with the precursor MJO event over the western Indian Ocean.

In a previous study, Hong et al. (2017) simulated three MJO events from 1 November through 31 December 2011 using COAMPS at 45- and 27-km horizontal resolution. They found that errors in the atmospheric forecast strongly project onto errors in the ocean when the simulation is coupled. In turn, these errors in the ocean then feedback to the atmosphere, and lead to errors in simulating the second of two MJO events. Overall, Hong et al. (2017) found the forecasts run at $27-\mathrm{km}$ resolution to be much more accurate in the strength and timing of MJO events than the $45-\mathrm{km}$ forecasts, with errors in the coarse-resolution simulations originating in the atmosphere and projecting onto the ocean rather than the other way around.

Using multiple reanalysis datasets, Sobel et al. (2014) and Li et al. (2015) focused on the first two MJO events of late October through December 2011 (hereafter MJO1 and MJO2). Sobel et al. (2014) found surface turbulent fluxes and radiative heating to be significant contributors to the MJO moist static energy budget. They also found horizontal moisture advection to be the dominant source moistening before MJO1, and also the dominant source of drying during the suppressed phase between events. $\mathrm{Li}$ et al. (2015) found the initiation of MJO1 was associated with anomalous vertical motion over the western Indian Ocean for greater than a week prior to initiation, while the initiation of $\mathrm{MJO} 2$ was more strongly related to anomalous horizontal advection of moisture. Consistent with earlier studies (e.g., Hsu and Li 2012), Sobel et al. (2014) and Li et al. (2015) both found that the eastward propagation of MJO1 and $\mathrm{MJO} 2$ are significantly modulated by the vertical advection of moisture. In essence, vertical advection provides relative moistening ahead of the active MJO and drying behind it.

Some recent research has focused on understanding of the interaction between the MJO and both convectively coupled atmospheric Kelvin waves (hereafter Kelvin waves; Kiladis et al. 2009) and equatorial Rossby waves (hereafter Rossby waves, Molinari et al. 2007). Guo et al. (2015) found models with more realistic Kelvin waves to produce more accurate MJO forecasts. Perhaps related to this finding, MacRitchie and Roundy (2012) found the interaction between Kelvin waves and the MJO to be complementary, with convection generated by the Kelvin wave serving as a source of potential vorticity (PV) for the MJO during and after the period in which the two features are spatially and temporally collocated. In contrast, Zhang and Ling (2012) found that neither Kelvin nor Rossby waves contribute significantly to the generation of MJO PV. The dynamics involved in the November 2011 events are made particularly complicated due to the presence of a series of Kelvin waves, a tropical cyclone (Reynolds et al. 2016), and a single distinct Rossby wave ( $\mathrm{Li}$ et al. 2015). However, our understanding of the effect of these various waves and disturbances in the evolution of cyclic MJO events remains incomplete.

In this study, we seek to explore differences in the ability of NAVGEM and COAMPS to predict the successive MJO events of November 2011 out to 30-day lead times, determine the importance of ocean coupling in these forecasts, and investigate the effect of using boundary conditions of varying realism for the COAMPS forecasts. We also seek to explore the ability of both of these models to predict Kelvin and atmospheric Rossby waves and their interactions with the $\mathrm{MJO}$ in the Indian Ocean region.

\section{Methodology}

\section{a. NAVGEM model configuration}

Global forecasts are produced using the Navy Global Environmental Model (NAVGEM) (Hogan et al. 2014). In this study, the model is run with a triangular truncation at wavenumber 359 (37-km effective horizontal resolution at the equator) and 50 vertical levels. Boundary layer mixing is parameterized with an eddy diffusivity mass flux (EDMF) scheme comprised of the eddy viscosity treatment of Louis et al. (1982) and an implementation of the mass flux parameterization of Sušelj et al. (2012). Cumulus convection is represented with a bimodal (turbulence and dynamically forced) extension of the modified Kain-Fritsch (KF) parameterization of Ridout et al. (2005). The model includes prognostic variables for cloud water and cloud ice, which are treated using an adaptation of the scheme of Zhao and Carr (1997). The NAVGEM forecasts are performed using three different ocean surface conditions: fixed SST (hereafter referred to as NAVGEM-F), observed SST updated 12-hourly (NAVGEM-O), and SST forced by coupling with the HYbrid Coordinate Ocean Model (HYCOM) (Bleck 2002) (NAVGEM-C). HYCOM is run for the NAVGEM-C runs at $1 / 12^{\circ}$ horizontal resolution, with an hourly coupling frequency. In the coupled run, NAVGEM and HYCOM are also coupled to the Community Ice Code (CICE), version 4.1 (Hunke and Lipscomb 2010). This coupled system is under development for transition to Navy operations for extended-range forecasting as the Navy Earth System Model (NESM). A summary of the three NAVGEM configurations appears in Table 1. 
TABLE 1. List of abbreviations for the NAVGEM simulations and their respective boundary conditions.

\begin{tabular}{cc}
\hline \hline Simulation & Lower boundary condition \\
\hline NAVGEM-F & Fixed SSTs \\
NAVGEM-O & Observed SSTs \\
NAVGEM-C & Coupled HYCOM \\
\hline
\end{tabular}

\section{b. COAMPS model configuration}

Regional simulations over the Indian Ocean region at higher horizontal resolution are performed using the U.S. Navy's Coupled Ocean-Atmosphere Mesoscale Prediction System (COAMPS; Hodur 1997). The model uses a terrain-following sigma-height coordinate and the nonhydrostatic compressible equations of motion (Klemp and Wilhelmson 1978). A more thorough description of COAMPS is provided by Hodur (1997) and Chen et al. (2003). In this study, all COAMPS simulations are run at $15-\mathrm{km}$ horizontal resolution, an increase in resolution with respect to the $45-$ and $27-\mathrm{km}$ grids used in Hong et al. (2017). There are 60 sigma levels in the vertical. The subgrid-scale moist convective processes are parameterized using a new simplified Arakawa-Schubert (SAS) scheme (Pan and Wu 1995). While we would ideally use a unified cumulus scheme for both the global and regional model, we found this particular configuration of COAMPS to produce a superior long-range forecast in the tropics using SAS versus KF. In the future, we plan to test and hopefully implement an upgraded version of KF in COAMPS that includes convective momentum transport. The planetary boundary layer and free atmospheric turbulent mixing and diffusion are parameterized following Mellor-Yamada's level 2.5 formulation (Mellor and Yamada 1982). Microphysics is specified via prognostic equations for mixing ratios of cloud droplets, ice particles, rain, snow, graupel, and drizzle following a modified parameterization based on Rutledge and Hobbs (1983) and Lin et al. (1983). An advanced fourstream radiation parameterization of $\mathrm{Fu}$ and Liou (1993) has been used to allow for aerosol, cloud, and radiation interactions (Liu et al. 2009).

Ocean coupling is active for all COAMPS simulations in this study using the Navy Coastal Ocean Model (NCOM, Martin 2000). The NCOM is a threedimensional, primitive equation, free-surface model using the hydrostatic, Boussinesq, and incompressible approximations and used as an oceanic component. The atmospheric model supplies a total of six ocean surface boundary forcing fields to the oceanic component, which provides a new sea surface temperature to the atmosphere that influences the prediction of the
TABLE 2. List of abbreviations for the COAMPS simulations and their respective lower and lateral boundary conditions.

\begin{tabular}{ccc}
\hline \hline Simulation & $\begin{array}{c}\text { Lower boundary } \\
\text { condition }\end{array}$ & $\begin{array}{c}\text { Lateral boundary } \\
\text { condition }\end{array}$ \\
\hline COAMPS-CF & Coupled NCOM & NAVGEM-F \\
COAMPS-CO & Coupled NCOM & NAVGEM-O \\
COAMPS-CC & Coupled NCOM & NAVGEM-C \\
\hline
\end{tabular}

atmospheric surface fluxes and wind stress at the next time step. These forcing fields include the sea level pressure, the surface wind stress components, the total heat and moisture fluxes and the net solar radiation. The two-way coupled system has been validated for air-sea interaction impact in various regions associated with a number of recent field campaigns (Allard et al. 2010; Hong et al. 2013; Chen et al. 2015; Hong et al. 2017). Initial conditions (ICs) and lateral boundary conditions (BCs) for COAMPS forecasts are provided by the three aforementioned NAVGEM simulations (NAVGEM-F, NAVGEM-O, and NAVGEM-C), to produce three corresponding COAMPS simulations, all coupled to NCOM: coupled COAMPS with NAVGEM-F (COAMPS-CF), coupled COAMPS with NAVGEM-O (COAMPS-CO), and coupled COAMPS with NAVGEM-C (COAMPS-CC). Initial and lateral boundary conditions for NCOM are from the $1 / 8^{\circ}$ resolution global NCOM. Both atmospheric and oceanic lateral boundary conditions are updated at a 6-h frequency. A summary of the COAMPS simulations appears in Table 2. Note that of the six simulations summarized in Tables 1 and 2, NAVGEM-O and COAMPS-CO would not be possible to run in real time.

\section{c. Case selection and verification}

In this study, 30-day simulations are initialized at 0000 UTC 1 November 2011, ending at 0000 UTC 1 December 2011. This period was chosen due to its high levels of MJO activity, with one MJO event active at the start of the simulation, and a second MJO event that initiates approximately 20 days into the simulation (hereafter referred to as MJO1 and MJO2, respectively). Convection over the Indian Ocean is suppressed from day 10 through day 20 , between events. One of the goals of this study is to evaluate the ability of NAVGEM and COAMPS to predict the initiation of $\mathrm{MJO} 2$. A second objective is to analyze model output in order to understand the dynamical relationship between $\mathrm{MJO} 1$ and $\mathrm{MJO} 2$, if such a relationship exists.

Model-predicted precipitation is verified using the Tropical Rainfall Measuring Mission multisatellite 
precipitation analysis (TRMM product 3B42, Huffman et al. 2007). Mass fields, momentum, surface fluxes and SST forecasts are verified using 6-hourly analyses from the European Centre for Medium-Range Weather Forecasts (ECMWF) interim reanalysis (ERA-Interim, hereafter ERA-I) dataset at $0.25^{\circ}$ resolution (Dee et al. 2011). NAVGEM and COAMPS predicted anomalies (e.g., anomalous zonal wind) are computed with respect to daily 37-yr ERA-I climatology from 1979 to 2015. Outgoing longwave radiation (OLR) is obtained from the NOAA interpolated OLR dataset (Lee 2014). Velocity potential (VP), the inverse Laplacian of the divergence, is also computed for NAVGEM, COAMPS, and ERA-I (e.g., Haltiner and Williams 1980). VP has been found to produce a more coherent signal for tracking the MJO versus other metrics such as OLR during the MJO's convectively inactive phase in the western hemisphere (Ventrice et al. 2013). Note that when computing velocity potential for the COAMPS simulations, it is necessary to include the full NAVGEM boundary condition fields in order to solve the Laplacian globally.

To understand sources of drying and moistening, the local time derivative of specific humidity $q$ is computed as

$$
\frac{\partial q}{\partial t}=-\mathbf{V} \cdot \nabla q-\omega \frac{\partial q}{\partial p}-\frac{Q_{2}}{L}
$$

where $\omega$ is vertical velocity, $\mathbf{V}$ is the horizontal wind, $Q_{2}$ is the latent heating due to condensational and evaporational processes and subgrid-scale moisture flux convergence, and $L$ is the latent heat of condensation (Li et al. 2015). The three terms on the right-hand side correspond to: horizontal moisture advection, vertical moisture advection, and moistening/drying due to model physics and subgrid-scale processes, respectively. In this study, we obtain $\partial q / \partial t$ directly from the model, but do not directly output $Q_{2}$. Therefore, we will compute the model physics term as the residual balancing the moisture tendency:

$$
-\frac{Q_{2}}{L}=\frac{\partial q}{\partial t}+\mathbf{V} \cdot \nabla q+\omega \frac{\partial q}{\partial p}
$$

Additionally, surface heat flux will be investigated to better understand the atmosphere-ocean interaction. Total net heat flux $H$ is defined as

$$
H=\mathrm{LH}+\mathrm{SH}+\mathrm{LW}+\mathrm{SW},
$$

where $\mathrm{LH}$ is latent heat flux, $\mathrm{SH}$ is sensible heat flux, $\mathrm{LW}$ is longwave radiation, and SW is shortwave radiation. In this paper, fluxes are defined such that positive values correspond to ocean warming.

\section{d. Wavenumber-frequency filtering}

A wavenumber-frequency filtering technique developed by Janiga et al. (2018) is applied to the model forecasts in order to isolate the component of the flow and OLR signals associated with low-frequency (>100 day), MJO, Kelvin, and Rossby waves. To filter for time scales longer than the 30-day model forecasts, the model forecasts are padded with $1 \mathrm{yr}$ of observations prior to the model initialization time and $1 \mathrm{yr}$ of zeroes after the completion of the forecast. The filtering is applied to zonal wind anomalies, velocity potential anomalies, and OLR anomalies. Model forecasts are padded with ERA-I data for the zonal wind and velocity potential forecasts and NOAA OLR for the OLR forecasts. While the location and phase speed of the waves is unaffected by the padded wavenumber-frequency filtering technique, the amplitude of the low-frequency and MJO signals are underestimated by $20 \%-40 \%$ in the final days of the forecast [see Fig. 3 of Janiga et al. (2018)]. The amplitude of the Kelvin and Rossby wave signals is less affected by the padded filtering technique due to their higher frequency.

\section{NAVGEM simulations}

While our ultimate goal is to assess the performance of the regional system, we begin by evaluating the performance of the global system to better understand the limitations of the lateral boundary conditions provided to COAMPS, and the reasons for these limitations. Three 30-day NAVGEM simulations are examined: NAVGEM-F, NAVGEM-O, and NAVGEM-C, all initialized at 0000 UTC 1 November 2011. Comparisons are made using ERA-I as verification for wind and velocity potential. In terms of anomalous zonal wind at $850 \mathrm{hPa}$ (hereafter u850 anomalies), all three NAVGEM simulations are too slow in propagating the anomalous westerlies associated with MJO1 eastward, although NAVGEM-C is the closest to reality (Fig. 1). Both NAVGEM-F and NAVGEM-O essentially stall MJO1 over the Maritime Continent, approximately $100^{\circ}-$ $150^{\circ} \mathrm{E}, 15$ days into the forecast or midway through the month of November. MJO2 clearly initiates in NAVGEM-C near the end of November, with highly accurate timing and magnitude when compared to ERA-I. On the other hand, $\mathrm{MJO} 2$ is somewhat too weak in NAVGEM-O and is virtually nonexistent in NAVGEM-F. These results are somewhat surprising, in that $\mathrm{MJO} 2$ appears to initiate at the right time in the coupled model even though the propagation speed associated with the first event appears to be far too 

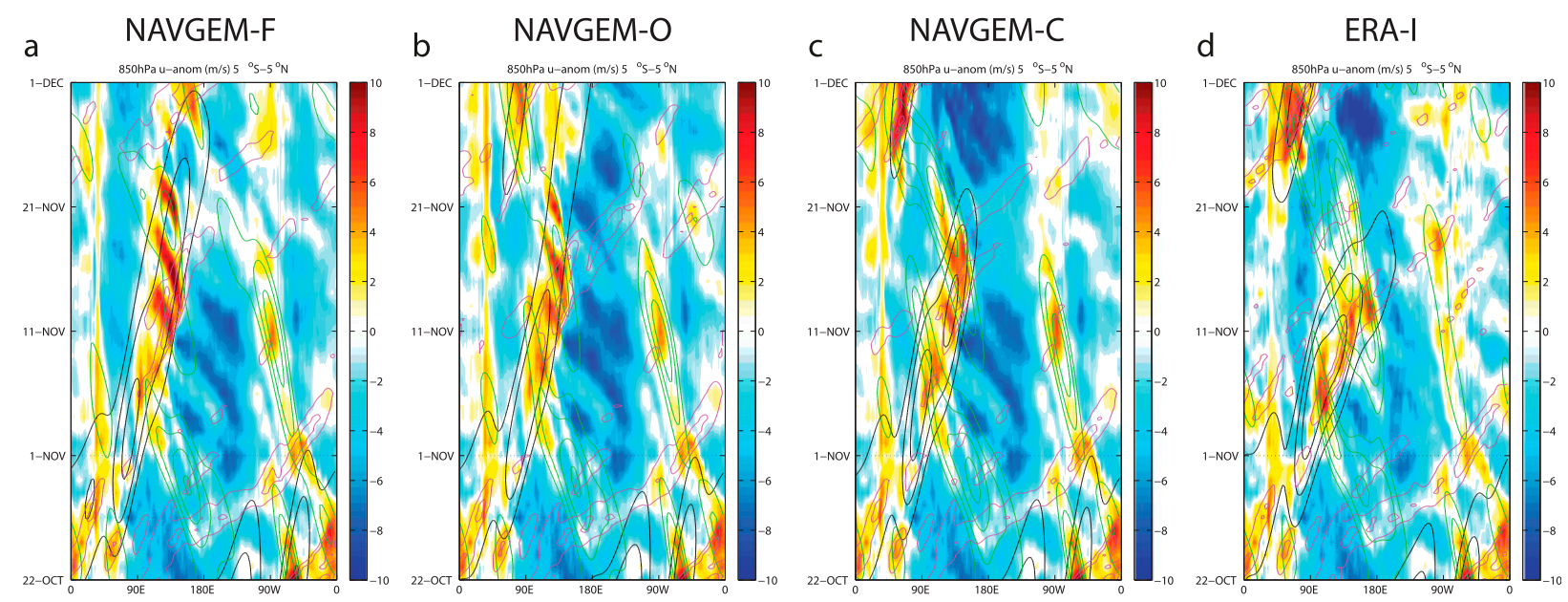

FIG. 1. Hovmöller diagrams of $850 \mathrm{hPa} u$ anomaly $\left(\mathrm{m} \mathrm{s}^{-1}\right.$, shaded) from $5^{\circ} \mathrm{S}$ to $5^{\circ} \mathrm{N}$ over all longitudes from (a) NAVGEM-F, (b) NAVGEM-O, (c) NAVGEM-C, and (d) ERA-I. Contoured are wavenumber-frequency filtered $u$ anomalies (only positive values, every $1 \mathrm{~m} \mathrm{~s}^{-1}$ ) associated with the MJO (black), Rossby waves (green), and Kelvin waves (magenta). Simulations are initialized 1 Nov; all data before 1 Nov are from ERA-I.

slow. This suggests that processes regulating successive events can be more regional and associated with ocean processes rather than global and associated with a circumnavigating atmospheric signal.

Several other notable phenomena are apparent in the $\mathrm{u} 850$ Hovmöllers. Perhaps the most notable feature is an atmospheric equatorial Rossby wave that initiates around 5 November in ERA-I from approximately $150^{\circ} \mathrm{E}-180^{\circ}$, over the west Pacific, just ahead of MJO1. The Rossby wave then strengthens as it travels westward before interacting with $\mathrm{MJO} 2$ in the final week of November. While this Rossby wave is generated slightly later in NAVGEM-C, and is somewhat weak biased in NAVGEM-O, the overall theme in the models is the same. Consistent with ERA-I, the Rossby wave in the NAVGEM forecasts initiates slightly east of MJO1 in mid-November, propagates westward and strengthens, and finally interacts with MJO2 around 25 November. In both reanalysis and forecasts, the u850 anomalies associated with $\mathrm{MJO} 2$ strengthen rapidly during this interaction. In contrast, note that the eastward propagation of u850 anomalies associated with MJO1 circumnavigates the globe too slowly to have a meaningful contribution to the initiation of MJO2 over the Indian Ocean. There also appear to be several Kelvin waves that interact with both MJO1 and MJO2 in the NAVGEM forecasts and ERA-I, although none of these Kelvin waves are associated with a continuous globally circumnavigating signal linking the two MJO events.

The anomalous 200-hPa velocity potential (vp200 anomaly, Fig. 2) signal for both $\mathrm{MJO} 1$ and $\mathrm{MJO} 2$ propagates at approximately the same forward speed, albeit slightly east (ahead) of the signal in u850. This slight difference in location is consistent with the fact that the greatest upper-level convergence and low-level divergence associated with the MJO occurs to the east of the strongest wind anomalies, in the region where the $u$-anomalies change sign. Consistent with the $\mathrm{u} 850$ anomaly Hovmöller diagrams, the most realistic MJO2 is produced by NAVGEM-C, while the least realistic forecast is produced by NAVGEM-F. There is perhaps some evidence of a globally circumnavigating signal associated with MJO1 reaching the Indian Ocean around 15 November in ERA-I, although it is somewhat unclear whether the negative vp200 anomalies that originate around $45^{\circ} \mathrm{W}$ are actually associated with MJO1 or are independently the early stages of an organizing MJO2. These certainly appear to be distinct events in the NAVGEM simulations. In either case, the upper-level signal associated with a Kelvin wave initiated over the Indian Ocean during MJO1 appears to circumnavigate the globe, reemerging over the Indian Ocean around 23 November. MJO2 strengthens significantly during its interaction with this Kelvin wave. This Kelvin wave and subsequent interaction with $\mathrm{MJO} 2$ is predicted in both NAVGEM-O and NAVGEM-C, with timing differences on the order of a few days. The westward-propagating Rossby wave is also apparent in vp200, although the signal is not quite as coherent in the NAVGEM forecasts.

Narrowing our focus to the convectively active longitudes of the $\mathrm{MJO}$ from $30^{\circ}$ to $150^{\circ} \mathrm{E}$, it is clear that NAVGEM-F fails to produce any meaningful precipitation (Fig. 3) or OLR anomalies (Fig. 4) associated with MJO2. Both precipitation and OLR are examined, since precipitation is a better proxy for heating rates while 

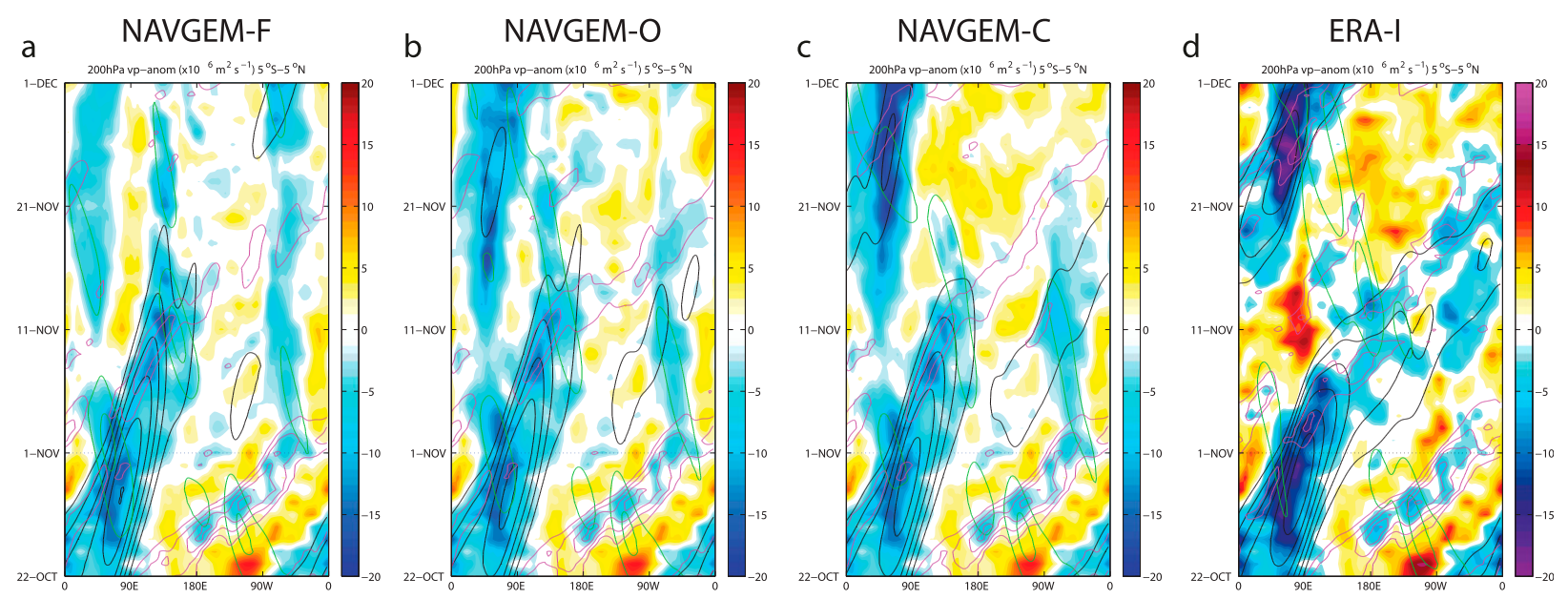

FIG. 2. As in Fig. 1, but for $200 \mathrm{hPa}$ VP anomaly $\left(\times 10^{6} \mathrm{~m}^{2} \mathrm{~s}^{-1}\right)$. Contoured are wavenumber-frequency filtered VP anomalies (only negative values, every $2 \times 10^{6} \mathrm{~m}^{2} \mathrm{~s}^{-1}$ ) associated with the MJO (black), Rossby waves (green), and Kelvin waves (magenta). Simulations are initialized 1 Nov; all data before 1 Nov are from ERA-I.

our wavenumber-frequency filtering technique was better-able to capture the MJO using OLR. While it was apparent in terms of $\mathrm{u} 850$ and vp200 that NAVGEM-C is better-representing the magnitude of $\mathrm{MJO} 2$ than NAVGEM-O, differences between the two runs in predicted precipitation and OLR are subtle. The dynamical connection between MJO1 and $\mathrm{MJO} 2$ via the Rossby wave is also more subtle in OLR than either u850 or vp200. It is noted that both NAVGEM-O and NAVGEM-C do a fairly good job in representing the major features and timing of $\mathrm{MJO} 2$ in the precipitation field. However, the OLR signature of the MJO is too strong in these runs, and the diurnal signal in the precipitation is overly pronounced ${ }^{1}$.

Finally, the SST anomalies are examined (Fig. 5). In ERA-I, a distinct period of SST warming occurs over the Indian Ocean from 5 to 25 November, occurring temporally between MJO1 and MJO2, during a period of positive OLR anomalies and weaker low-level winds. A sudden cooling occurs from 25 November through 1 December as MJO2 organizes and strengthens. Presumably this cooling is due to a combination of reduced incoming shortwave radiation due to increased cloud cover, increased latent heat exchange due to stronger surface wind, and ocean mixing. Surface fluxes will be examined in greater detail in the following section. SSTs do not change throughout the forecast in the NAVGEM-F simulation per definition, although there is a subtle change in the anomalies from 1 November

\footnotetext{
${ }^{1}$ Testing of the convective scheme and microphysics is ongoing to improve predicted OLR and convective precipitation in coupled NAVGEM-HYCOM.
}

through 1 December as the climatology used as a baseline to define these anomalies evolves slightly. Compared to ERA-I, NAVGEM-O analyses as provided by $\mathrm{HYCOM}$ appear to be up to $0.5^{\circ} \mathrm{C}$ warmer throughout the Indian Ocean and west Pacific regions. Last, with fully coupled atmosphere-ocean interaction, NAVGEM-C produces a forecast that is quite consistent with ERA-I, albeit with slightly too much warming in mid-November and too much cooling associated with $\mathrm{MJO} 2$ in late November. The cool bias in the west Pacific in the NAVGEM-C simulation is likely a consequence of too much cloud cover in the region ${ }^{2}$, as evidenced by the negative OLR anomalies in Fig. 4.

To summarize, NAVGEM produces a reasonable MJO2 when using observed SSTs for the lower boundary condition or when coupled with HYCOM, but fails to produce MJO2 when using fixed SSTs. Unfortunately, observed SSTs are not available for real-time forecasts, while coupling globally to HYCOM is computationally expensive. Therefore, in the next section, we will evaluate the performance of a regionally coupled COAMPS simulation with lateral boundary conditions from the inexpensive NAVGEM-F run. It is also intriguing that the NAVGEM forecast with coupled SSTs performed better than the forecast using observed SSTs. We suspect that this has to do with the complicated nature of the interaction between convection and SSTs, as discussed by DeMott et al. (2015). In the coupled

\footnotetext{
${ }^{2}$ While the NAVGEM-F and NAVGEM-O simulations also have too much cloud cover in the west Pacific, the lack of full ocean coupling prevents the development of the cool bias characteristic of the NAVGEM-C simulation.
} 

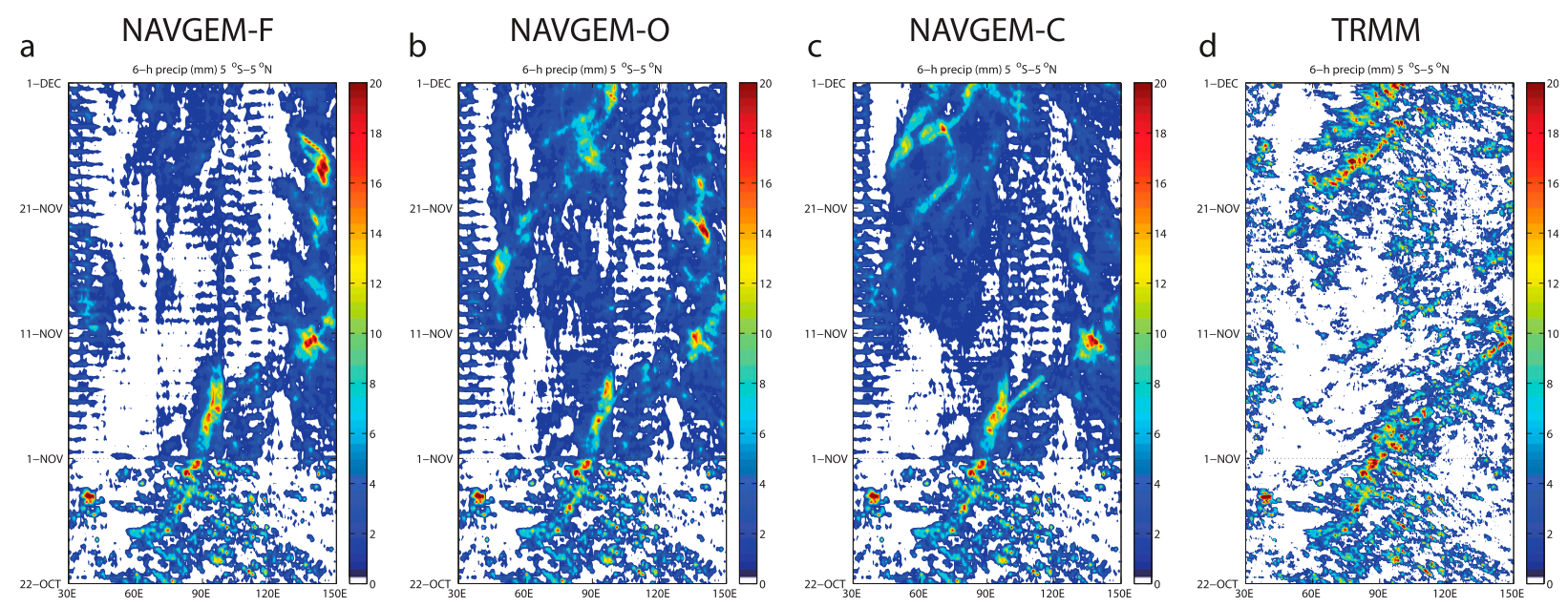

FIG. 3. Hovmöller diagrams of 6-h precipitation (mm, shaded) from $5^{\circ} \mathrm{S}-5^{\circ} \mathrm{N}, 30^{\circ}-150^{\circ} \mathrm{E}$ from (a) NAVGEM-F, (b) NAVGEM-O, (c) NAVGEM-C, and (d) TRMM. Simulations are initialized 1 Nov; all data before 1 Nov are from TRMM.

simulation, SST cooling generally occurs as a response to convection, after convection has already been occurring for some time and organized upscale. On the other hand, using observed SST can be detrimental when the timing or location of convective initiation is slightly off. If SSTs are forced to cool beneath developing convection, the convection will weaken before reaching its full potential.

\section{COAMPS simulations}

\section{a. Horizontal structure}

Next we attempt to simulate the successive MJO events of November 2011 with COAMPS using the three different NAVGEM simulations from section 3 as boundary conditions. The COAMPS domain encompasses the region from $27^{\circ} \mathrm{S}$ to $27^{\circ} \mathrm{N}, 30^{\circ}-150^{\circ} \mathrm{E}$, which contains the Indian Ocean and Maritime Continent (Fig. 6). COAMPS simulations are summarized in Table 2. Somewhat surprisingly, the results from all three simulations are remarkably similar in terms of u850 (Fig. 7), vp200 (Fig. 8), and simulated reflectivity (Fig. 9), despite the obvious differences in lateral boundary conditions. These simulations appear to be quite skillful in terms of timing the lull in activity between MJO events, the initiation of $\mathrm{MJO} 2$, as well as correctly predicting the eastward propagation speed of both MJO events while they are over the Indian Ocean. What is particularly noteworthy is that COAMPS-CF is able to reproduce $\mathrm{MJO} 2$ when the second $\mathrm{MJO}$ does
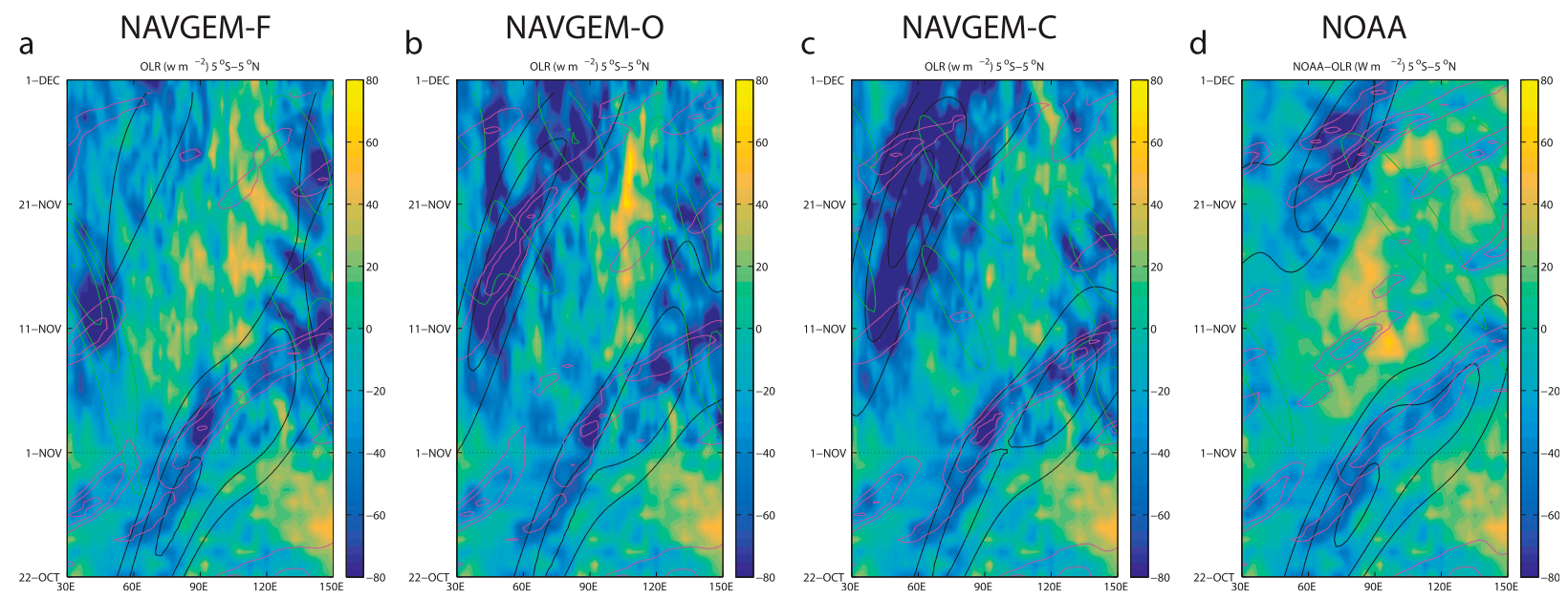

FIG. 4. Hovmöller diagrams of $24-\mathrm{h}$ average OLR anomalies ( $\mathrm{W} \mathrm{m}{ }^{-2}$, shaded) from $5^{\circ} \mathrm{S}-5^{\circ} \mathrm{N}, 30^{\circ}-150^{\circ} \mathrm{E}$ from (a) NAVGEM-F, (b) NAVGEM-O, (c) NAVGEM-C, and (d) NOAA OLR. Contoured are wavenumber-frequency filtered OLR anomalies (only negative values, every $10 \mathrm{~W} \mathrm{~m}^{-2}$ ) associated with the MJO (black), Rossby waves (green), and Kelvin waves (magenta). Simulations are initialized 1 Nov; all data before 1 Nov are from NOAA. 

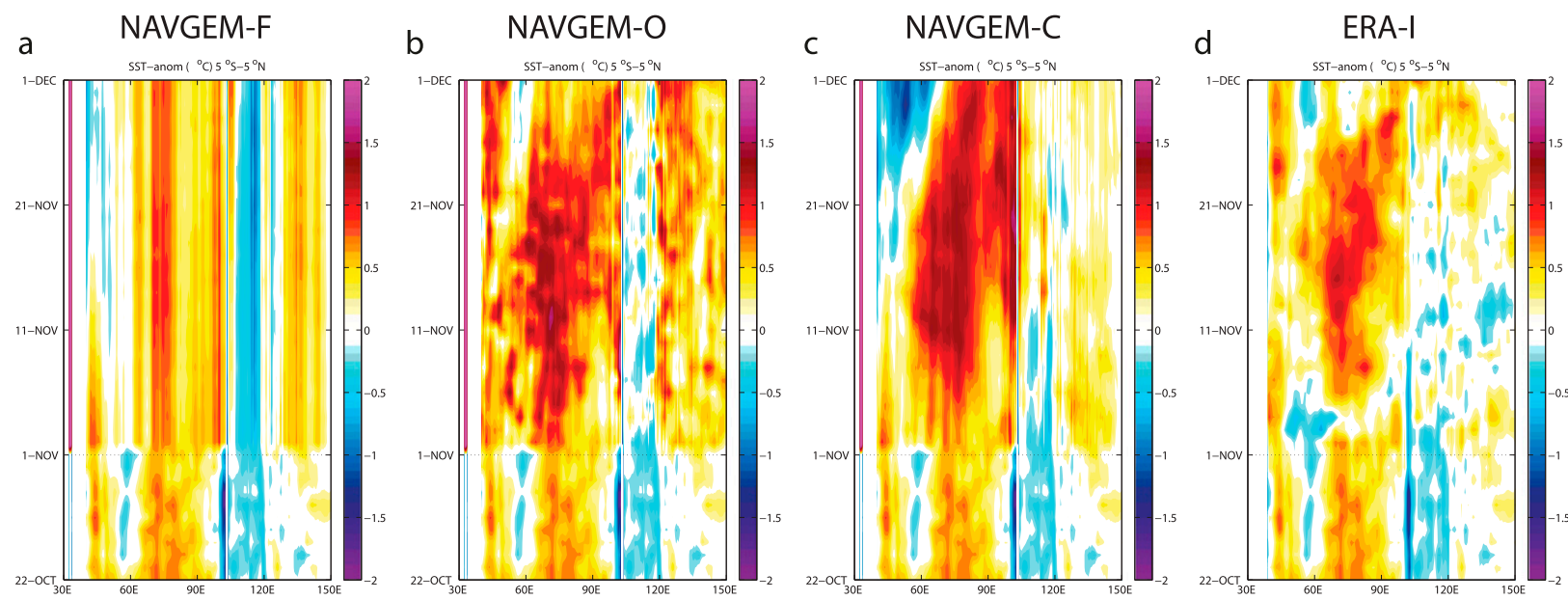

FIG. 5. Hovmöller diagrams of SST anomaly $\left({ }^{\circ} \mathrm{C}\right.$, shaded) from $5^{\circ} \mathrm{S}-5^{\circ} \mathrm{N}, 30^{\circ}-150^{\circ} \mathrm{E}$ from (a) NAVGEM-F, (b) NAVGEM-O,

(c) NAVGEM-C, and (d) ERA-I. Simulations are initialized 1 Nov; all data before 1 Nov are from ERA-I.

not exist at all in the parent model (NAVGEM-F). This suggests that processes occurring within the COAMPS regional domain are sufficient to trigger $\mathrm{MJO} 2$ and overcome deficiencies in the lateral boundary conditions.

Overall, the COAMPS simulations are quite successful in predicting the onset of an MJO event with $>20$ days lead time. The period of suppressed convection over the west through central Indian Ocean from 1 to 15 November is well predicted (Fig. 9). The effect of this period of suppressed convection on surface fluxes will be discussed in the next subsection. The westward propagation of the Rossby wave associated with MJO1 over the Maritime Continent, and its subsequent interaction with $\mathrm{MJO} 2$ over the western Indian Ocean around 25 November, is also well captured in these simulations. As MJO2 intensifies significantly at both lower levels (Fig. 7) and upper levels (Fig. 8) during this interaction, this Rossby wave appears to be a critical piece to the puzzle. Interestingly, the Rossby wave is almost equally well captured in all three COAMPS simulations, suggesting that it is more critical to capture processes internal to the COAMPS domain versus boundary conditions that do not have much effect on it. Therefore, it is likely that the ability of COAMPS to accurately predict the motion and interaction of this Rossby wave with both MJO events results in increased predictability for $\mathrm{MJO} 2$.

There are some deficiencies in the COAMPS simulations, the most obvious one being a large strong bias associated with $\mathrm{MJO} 2$ in terms of positive u850 (Fig. 7) and negative vp200 (Fig. 8) anomalies. COAMPS also produces slightly too much precipitation overall throughout the 30-day period, but excessively suppresses precipitation during the convectively suppressed phase

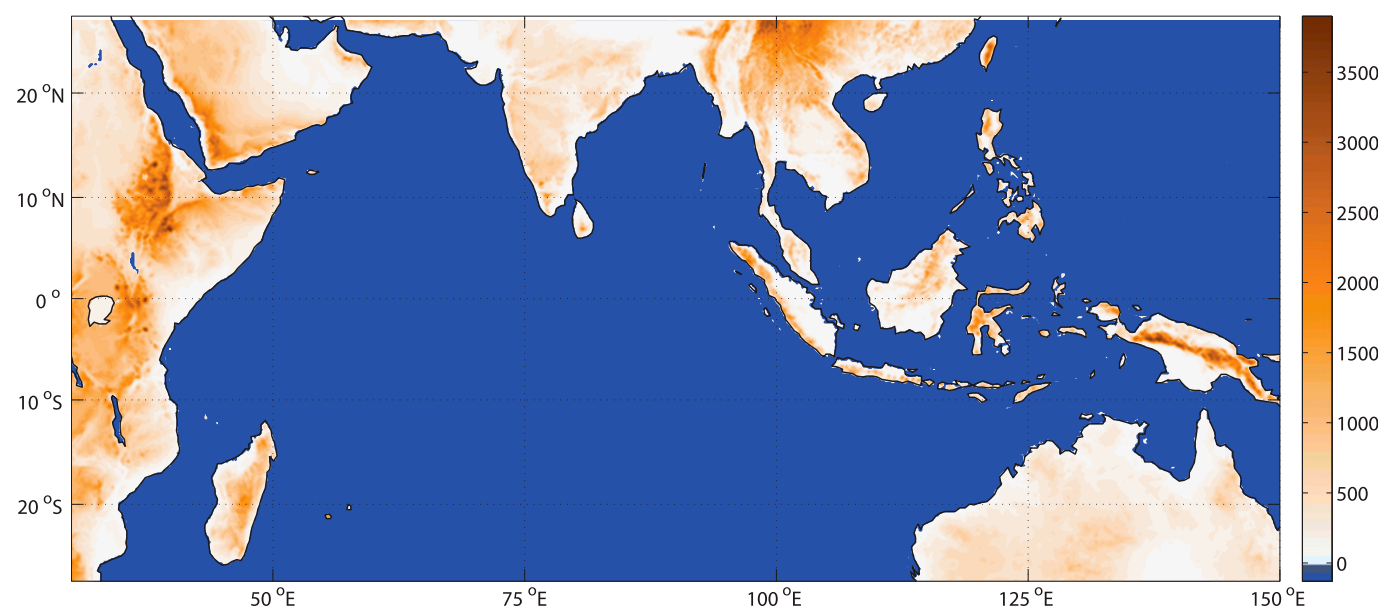

FIG. 6. Terrain height ( $\mathrm{m}$, shaded) for the COAMPS regional domain. 

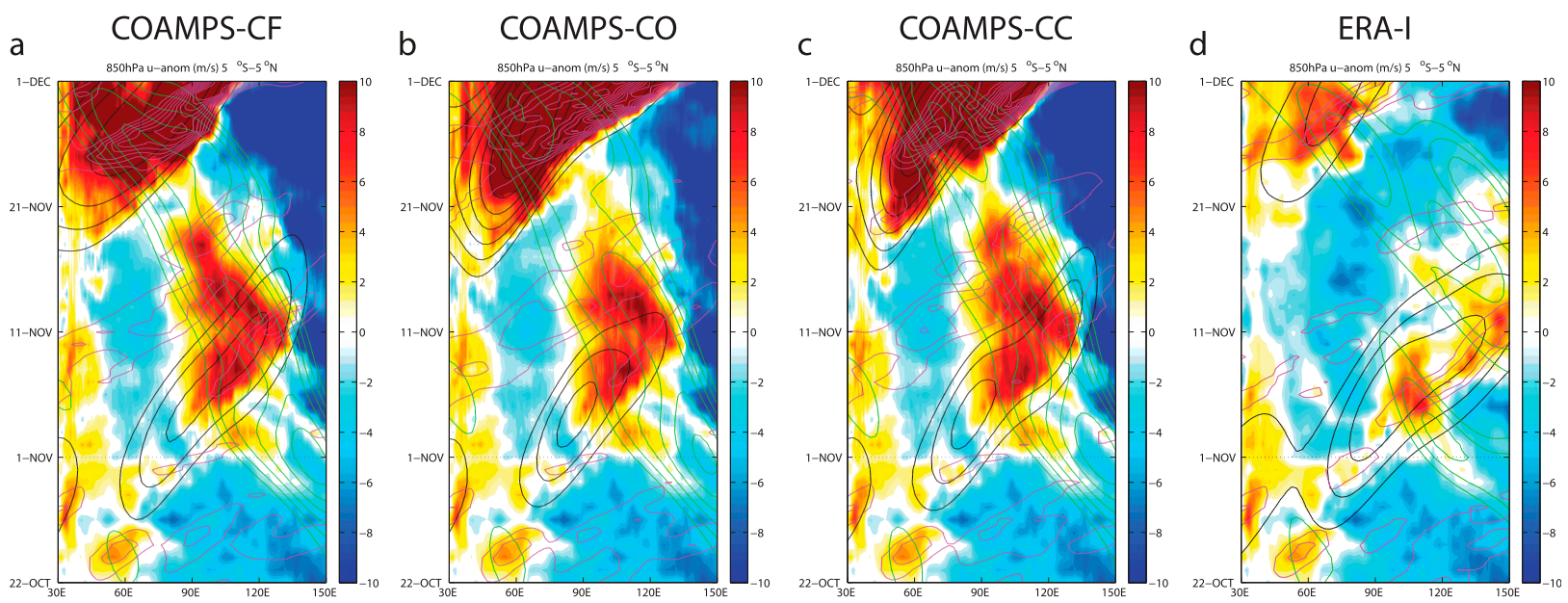

FIG. 7. Hovmöller diagrams of $850 \mathrm{hPa} u$ anomaly $\left(\mathrm{m} \mathrm{s}^{-1}\right.$, shaded) from $5^{\circ} \mathrm{S}-5^{\circ} \mathrm{N}, 30^{\circ}-150^{\circ} \mathrm{E}$ from (a) COAMPS-CF, (b) COAMPS-CO, (c) COAMPS-CC, and (d) ERA-I. Contoured are wavenumber-frequency filtered $u$ anomalies (only positive values, every $1 \mathrm{~m} \mathrm{~s}^{-1}$ ) associated with the MJO (black), Rossby waves (green), and Kelvin waves (magenta). Simulations are initialized 1 Nov; all data before 1 Nov are from ERA-I.

between MJO events (Fig. 9). Last, while the MJO signal does propagate through the Maritime Continent to some extent, the signal becomes somewhat weaker than observed as it is passing through this region, particularly in terms of u850 anomalies (Fig. 7).

We would like to better understand why COAMPS produces such a strong $\mathrm{MJO} 2$. In examining the SST fields (Fig. 10), it is apparent that the coupled COAMPS-NCOM system warms the western Indian Ocean excessively from approximately 5-20 November. Warmer SSTs generated during the convectively suppressed phase should result in greater surface heat fluxes during the onset of the convectively active phase, resulting in stronger convection which should drive a stronger MJO. Similarly, total precipitable water (TPW) anomalies are up to $5 \mathrm{~mm}$ too large throughout the COAMPS domain (Fig. 11). The availability of excessive moisture may also fuel unrealistically intense and long-lived convection. Note that the characteristic drying that usually occurs over the Indian Ocean between MJO events, while very obvious in ERA-I, is not apparent in the COAMPS runs. It is interesting that this drying is not evident even though precipitation during this suppressed phase is overly suppressed (Fig. 9). This may indicate a shortcoming in the model physics in how deep convection interacts with environmental moisture,
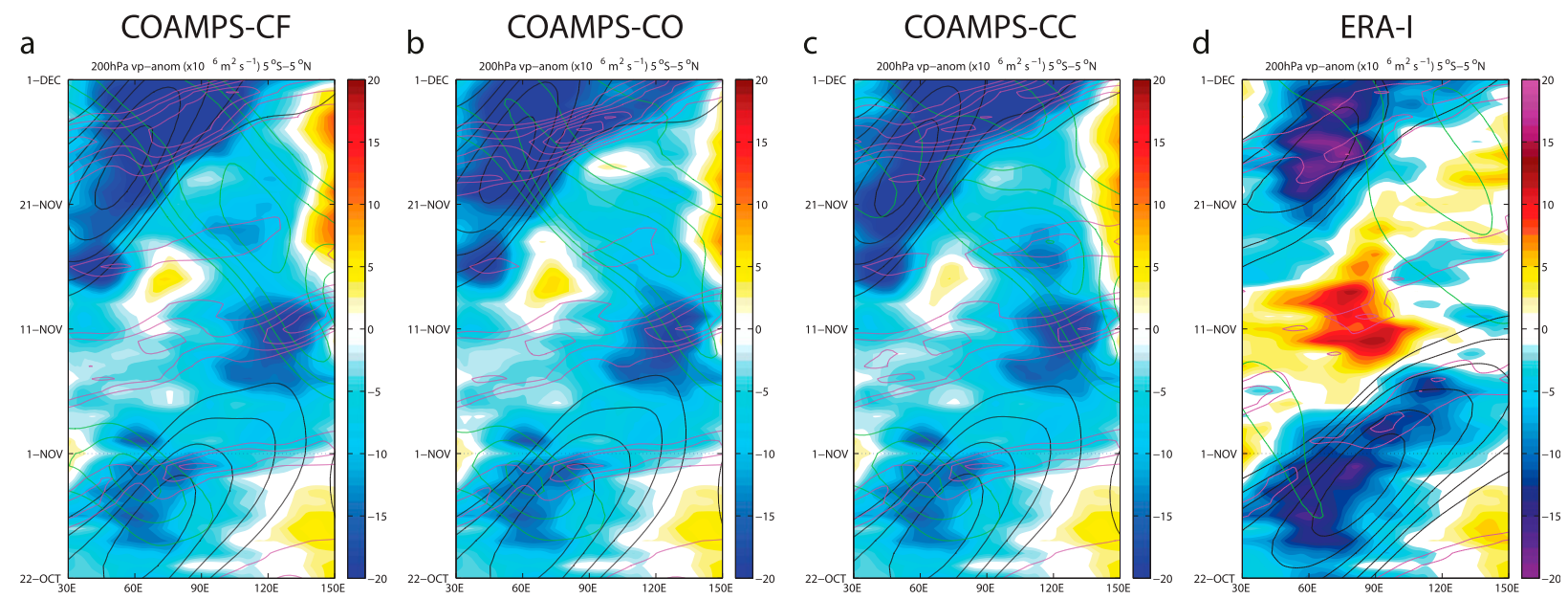

FIG. 8. As in Fig. 7, but for $200 \mathrm{hPa}$ VP anomaly $\left(\times 10^{6} \mathrm{~m}^{2} \mathrm{~s}^{-1}\right)$. Contoured are wavenumber-frequency filtered VP anomalies (only negative values, every $2 \times 10^{6} \mathrm{~m}^{2} \mathrm{~s}^{-1}$ ) associated with the MJO (black), Rossby waves (green), and Kelvin waves (magenta). Simulations are initialized 1 Nov; all data before 1 Nov are from ERA-I. 

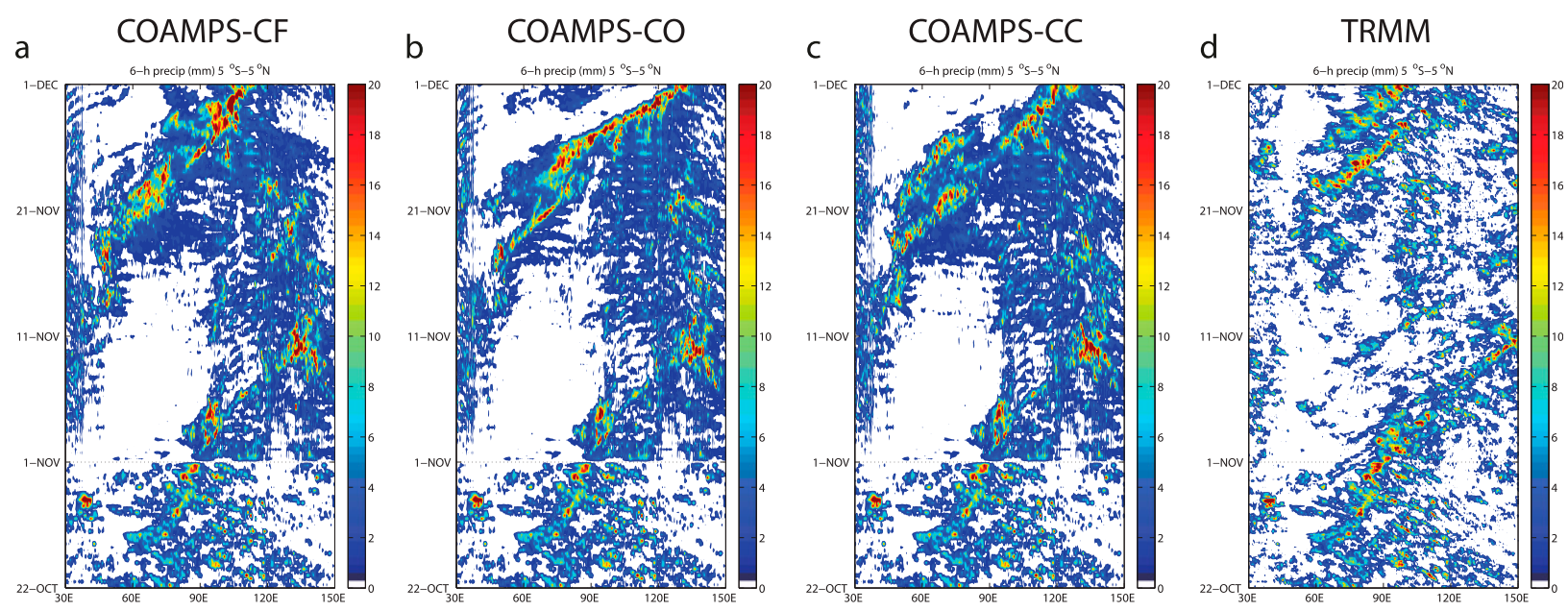

FIG. 9. Hovmöller diagrams of 6-h precipitation (mm, shaded) from $5^{\circ} \mathrm{S}-5^{\circ} \mathrm{N}, 30^{\circ}-150^{\circ} \mathrm{E}$ from (a) COAMPS-CF, (b) COAMPS-CO, (c) COAMPS-CC, and (d) TRMM. Simulations are initialized 1 Nov; all data before 1 Nov are from TRMM.

and will be investigated in a future study. While the initial suppressed phase is much too moist, significant drying does occur following $\mathrm{MJO} 2$, particularly in the COAMPS-CF and COAMPS-CC simulations. This shows that drying can still occur if the MJO is strong enough. All three COAMPS simulations overcool the SSTs following MJO2.

\section{b. Surface fluxes}

To understand the source of the SST warming in the COAMPS simulations, surface heat flux is examined. In both ERA-I and COAMPS-CC ${ }^{3}$, both MJO events correspond to periods of negative $H$, resulting in a cooling of the ocean surface (Fig. 12). The region of maximum ocean cooling also propagates eastward with the MJO. Both periods of negative $H$ are associated with a reduction in positive SW due to increased cloud cover, and increasingly negative LH due to enhanced surface wind (Fig. 13). Perhaps unsurprisingly, the largest error in COAMPS fluxes occurs in the LH near the end of November, when the unrealistically strong surface winds occur with $\mathrm{MJO} 2$. There is also a pronounced bias in LW, which is defined here as the difference between longwave radiation emitted by the ocean and longwave radiation received from the atmosphere. This is likely the result of the model having too much moisture (Fig. 11) and excessive cloud cover (not shown), both of which will result in increased downward emission of longwave radiation by the atmosphere.

\footnotetext{
${ }^{3}$ While we are only comparing with a single COAMPS simulation here, surface fluxes in all three simulations are qualitatively similar.
}

In contrast with the convectively active periods, the inactive period between the two MJO events is associated with consistently positive $H$, resulting in ocean warming (Fig. 12). The fact that the SSTs in COAMPS warm too much in mid-November appears to be due to a combination of the aforementioned positive bias in LW and a temporary positive bias in $\mathrm{LH}$ during this period. The enhanced ocean warming is partially offset by a negative bias in SW associated with the increased cloud cover. It does not appear that the warmer SSTs are contributing to increased latent or sensible heat flux into the atmosphere in the days leading up to the initiation of MJO2 (Fig. 13). However, the LH fluxes in the COAMPS forecast become significantly larger in magnitude than in ERA-I in the days following initiation, around 21 November, during which time the MJO is rapidly strengthening. These enhanced LH fluxes, fueled through a larger air-sea moisture difference and stronger low-level winds, are likely contributing to stronger convection. Therefore, it is likely that the warm bias in the SSTs is contributing to larger (negative) LH flux, which in turn is contributing to a bias in the strength of MJO2.

\section{c. Vertical evolution}

Pressure-time cross sections are examined to explore the ability of COAMPS to represent the vertical evolution of the successive MJO events. In this section, we are averaging values from $5^{\circ} \mathrm{S}$ to $5^{\circ} \mathrm{N}$ and from $50^{\circ}$ to $75^{\circ} \mathrm{E}$. Both $\mathrm{MJO} 1$ and $\mathrm{MJO} 2$ are associated with anomalous easterlies at upper levels, at and above $400 \mathrm{hPa}$, and anomalous westerlies at lower levels to middle levels, from the surface through $500 \mathrm{hPa}$. The magnitude of the low-level westerly anomaly associated with $\mathrm{MJO} 2$ is much stronger than that associated 

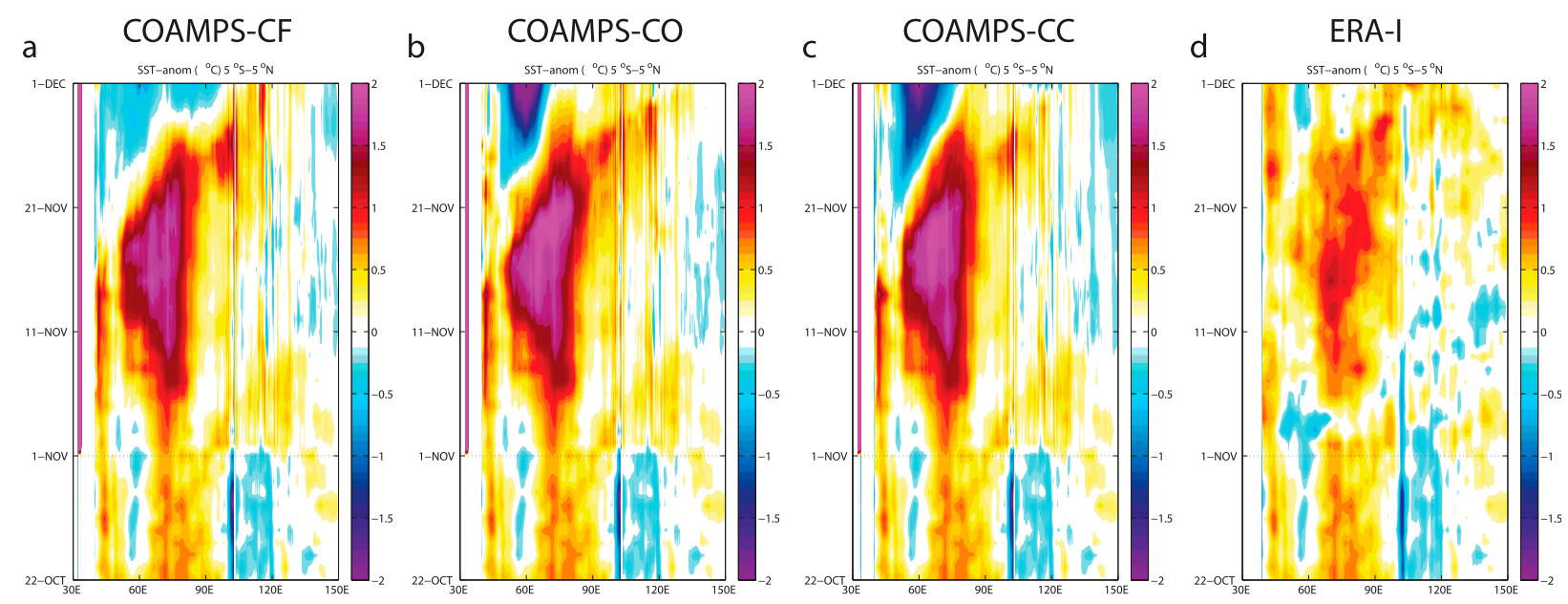

FIG. 10. Hovmöller diagrams of SST anomaly $\left({ }^{\circ} \mathrm{C}\right.$, shaded) from $5^{\circ} \mathrm{S}-5^{\circ} \mathrm{N}, 30^{\circ}-150^{\circ} \mathrm{E}$ from (a) COAMPS-CF, (b) COAMPS-CO,

(c) COAMPS-CC, and (d) ERA-I. Simulations are initialized 1 Nov; all data before 1 Nov are from ERA-I.

with MJO1 in both the COAMPS forecast ${ }^{4}$ (Fig. 14a) and ERA-I (Fig. 14b). However, the magnitude of the $u$-anomaly associated with $\mathrm{MJO} 2$ is also significantly greater in COAMPS than it is in ERA-I, as previously discussed. Interestingly, the characteristic drying that occurs between most MJO events, the November 2011 event included (Fig. 14d), is not immediately evident in the COAMPS forecast (Fig. 14c). As will be elaborated on later in this subsection, drying is occurring during this timeframe. However, because the COAMPS base-state is so moist, anomalies are not evident when computed against the ERA-I mean. Along those lines, the period of $\mathrm{MJO} 2$ is accompanied by an even greater moisture anomaly than any period before it in COAMPS, particularly from 900 to $500 \mathrm{hPa}$, so mid-November is somewhat dry compared to late November. However, COAMPS does not fail to produce anomalous drying in the wake of all MJO events, as distinct drying occurs throughout the troposphere in the final 5 days of the simulation following the passage of $\mathrm{MJO} 2$.

Next, horizontal divergence and vertical motion $\omega$ are examined. For both MJO events, the strongest upperlevel divergence (Figs. 15a,b) occurs temporally in conjunction with the greatest negative $\omega$ (Figs. 15c,d). This is perhaps unsurprising, as upper-level divergence and $\omega$ are intimately related through the convection (and through continuity). In ERA-I, there is a period of several days following the passage of MJO1 in which there is weak low-level convergence and little $\omega$. Low-level horizontal convergence suddenly begins to strengthen around 11 November, with increasingly negative

\footnotetext{
${ }^{4}$ Note that while only the COAMPS-CC simulation is shown here, all three COAMPS simulations are qualitatively similar.
}

$\omega$ shortly thereafter. The vertical level of greatest horizontal convergence gradually builds upward with time, first from the surface through $800 \mathrm{hPa}$ from 11 to 21 November, then from 600 to $300 \mathrm{hPa}$ from 22 November through 1 December. The level of greatest vertical motion also rises throughout this period, but almost always occurs above the level of maximum convergence at any given time. This makes sense, based upon common understanding of the in-up-out circulation associated with the MJO. While horizontal convergence dominates during the active MJO periods, the middle levels are associated with net horizontal divergence at the early stages of $\mathrm{MJO} 2$, while divergence develops at the lower levels in the later stages of MJO2. The evolution of the divergence structure is consistent with the evolution of convective heating from shallow, to deep, to stratiform. Overall, while COAMPS produces midlevel horizontal convergence and negative $\omega$ associated with $\mathrm{MJO} 2$ that are slightly too strong, the model depicts a very realistic evolution of both fields.

Finally, the time-tendency of moisture and its individual terms are examined. First, we examine the horizontal advection of moisture (Figs. 16a,b) and vertical advection of moisture (Figs. 16c,d). Overall, vertical advection of moisture leads to a moistening throughout the troposphere during both MJO events, while horizontal flow generally advects drier air into the Indian Ocean region throughout the period. It should be noted that the horizontal moisture advection is quite sensitive to the choice of longitudinal area over which one is averaging. For example, our results agree with Sobel et al. (2014), who found negative horizontal moisture advection in the preconditioning phase of $\mathrm{MJO} 2$ when averaging from $73^{\circ}$ to $80^{\circ} \mathrm{E}$. In contrast, Li et al. (2015) found positive horizontal moisture advection during this same 

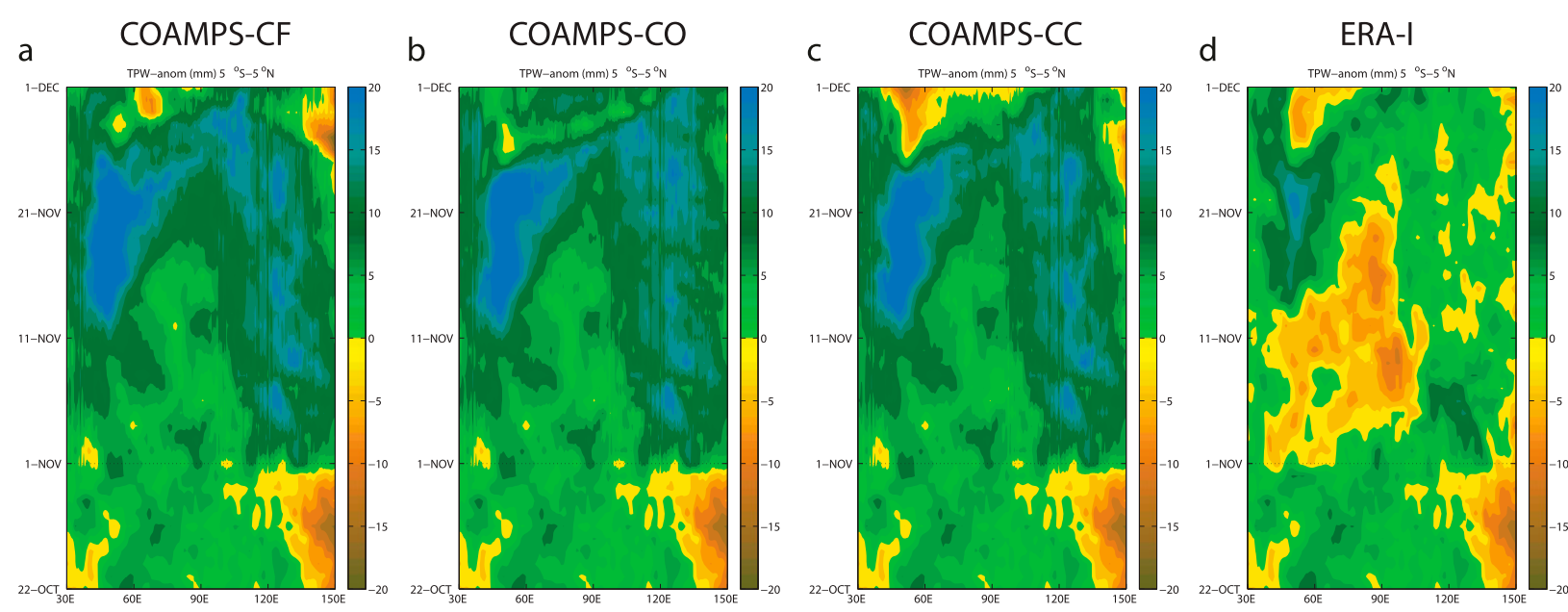

FIG. 11. Hovmöller diagrams of TPW anomaly (mm, shaded) from $5^{\circ} \mathrm{S}-5^{\circ} \mathrm{N}, 30^{\circ}-150^{\circ} \mathrm{E}$ from (a) COAMPS-CF, (b) COAMPS-CO, (c) COAMPS-CC, and (d) ERA-I. Simulations are initialized 1 Nov; all data before 1 Nov are from ERA-I.

timeframe, but averaging much farther west from $50^{\circ}-60^{\circ} \mathrm{E}$ to $45^{\circ}-65^{\circ} \mathrm{E}$. Other studies have shown that the horizontal advection of dry air is predominantly due to meridional advection from off-equatorial regions, and is enhanced during active MJO periods. Janiga and Zhang
(2016) describe an initial moistening at low to middle levels through shallow convection, followed by moistening at upper levels and drying at low levels due to moderate to deep convection. This transition is captured by COAMPS, albeit with slightly too sudden a transition

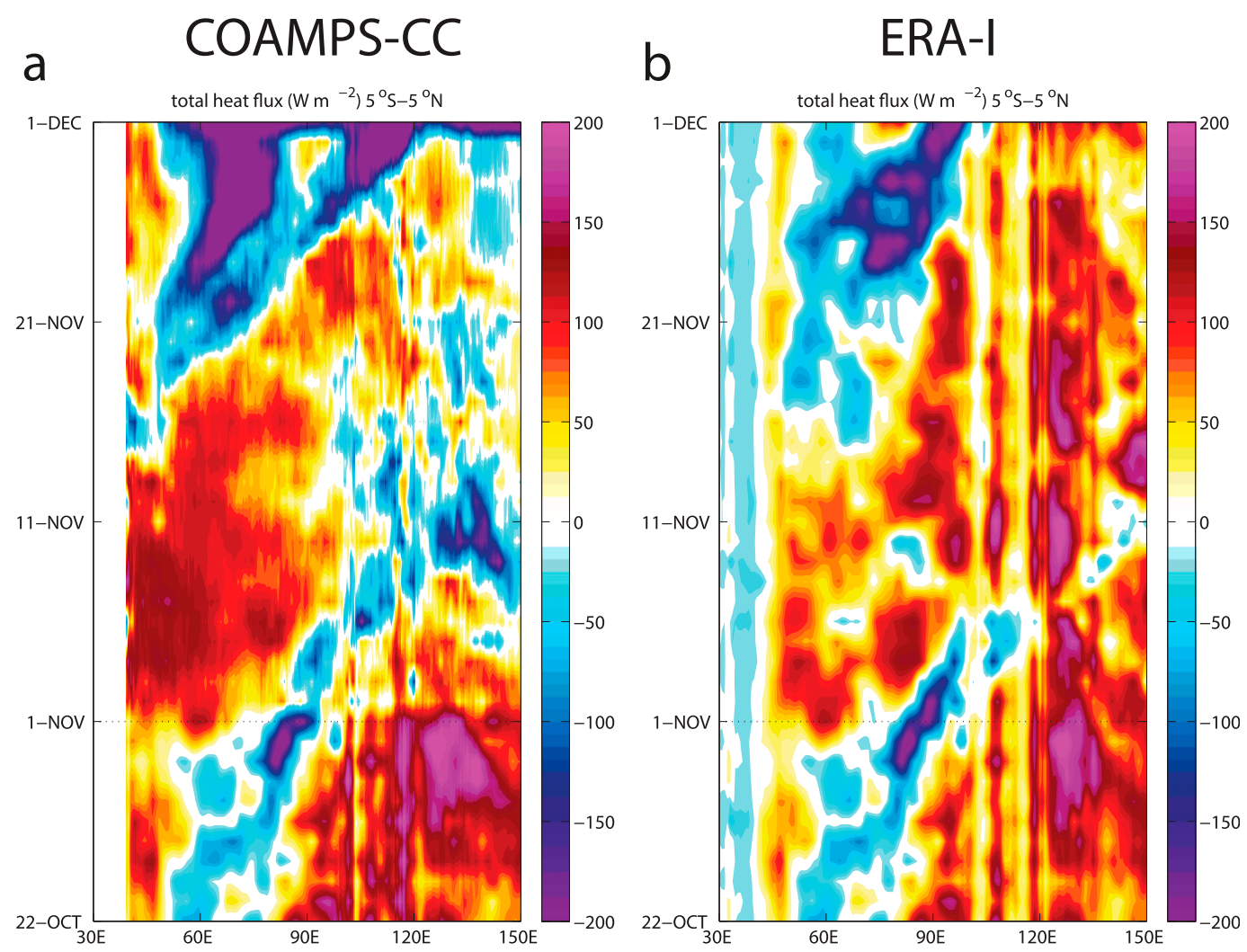

FIG. 12. Hovmöller diagrams of total heat flux ( $\mathrm{W} \mathrm{m}^{-2}$, shaded) from $5^{\circ} \mathrm{S}-5^{\circ} \mathrm{N}, 30^{\circ}-150^{\circ} \mathrm{E}$ from (a) COAMPS-CC and (b) ERA-I. Simulations are initialized 1 Nov; all data before 1 Nov are from ERA-I. 


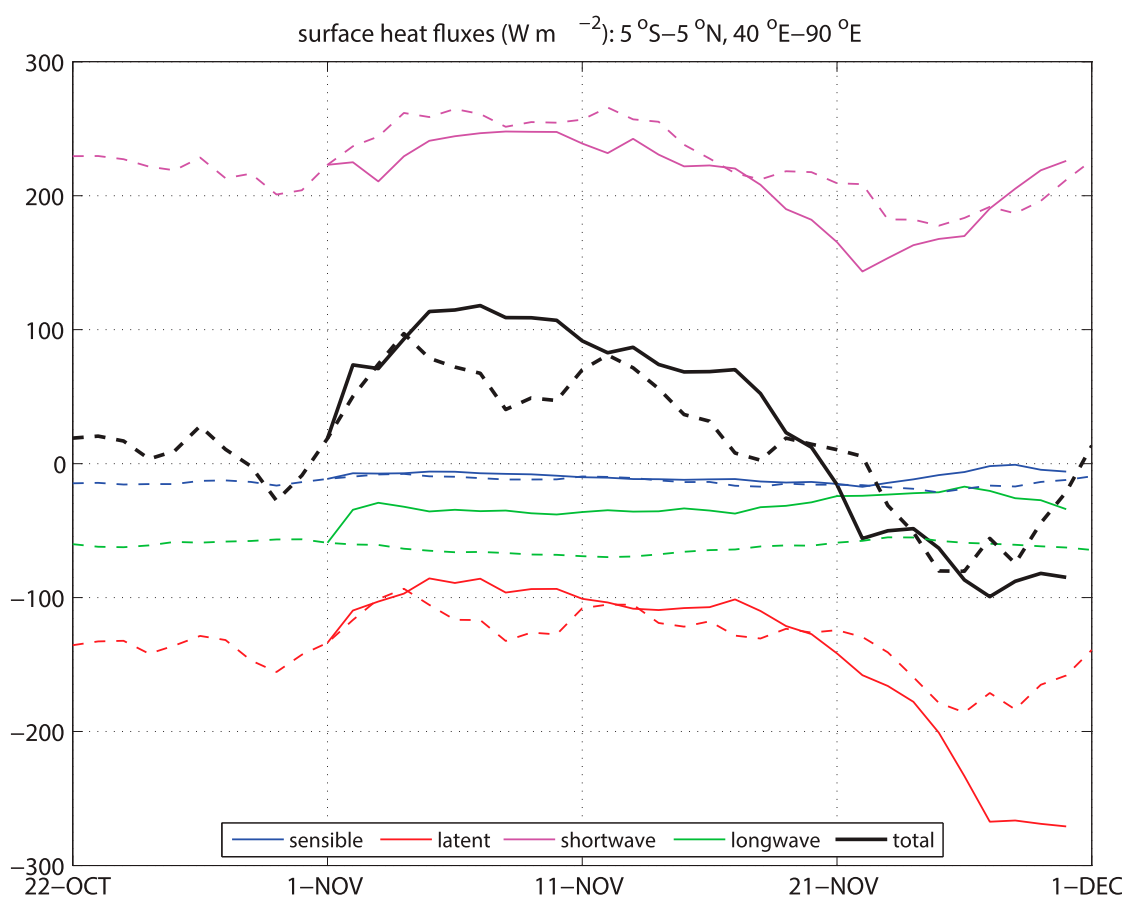

FIG. 13. Surface SH (blue), LH (red), SW (magenta), LW (green), and total $H$ (black), from COAMPS-CC (solid) and ERA-I (dashed). Positive values indicate ocean warming.

from drying to moistening and back to drying throughout the full depth of the troposphere.

Maximum moistening due to vertical advection occurs during the preconditioning phase and early into the mature phase of $\mathrm{MJO} 2$, from 13 to 21 November, with moistening rates exceeding $1 \mathrm{~g} \mathrm{~kg}^{-1} \mathrm{day}^{-1}$ from 900 to $400 \mathrm{hPa}$ throughout the period. However, much of this moistening due to vertical advection is canceled
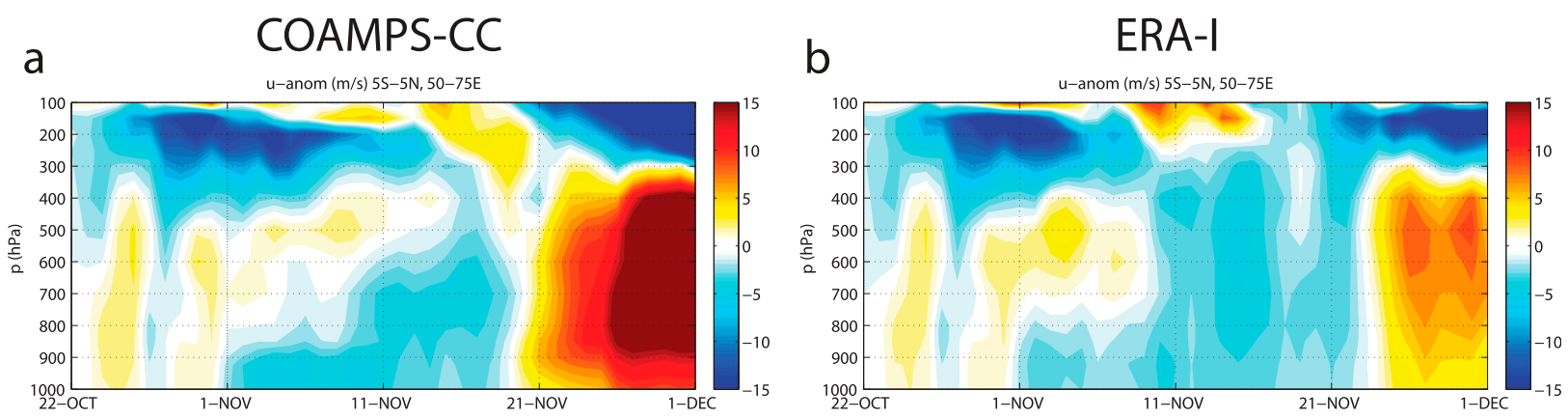

C

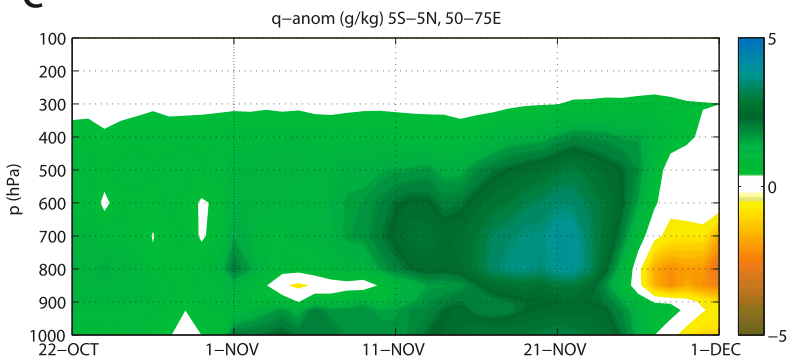

d

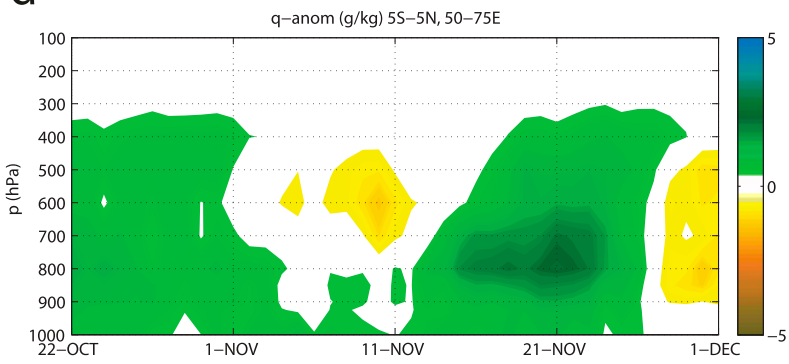

FIG. 14. Time-pressure cross sections of (a),(b) $u$ anomaly $\left(\mathrm{m} \mathrm{s}^{-1}\right)$ and (c),(d) $q$ anomaly $\left(\mathrm{g} \mathrm{kg}^{-1}\right)$ from (a),(c) COAMPS-CC and (b),(d) ERA-I, averaged from $5^{\circ} \mathrm{S}-5^{\circ} \mathrm{N}, 50^{\circ}-75^{\circ} \mathrm{E}$. 

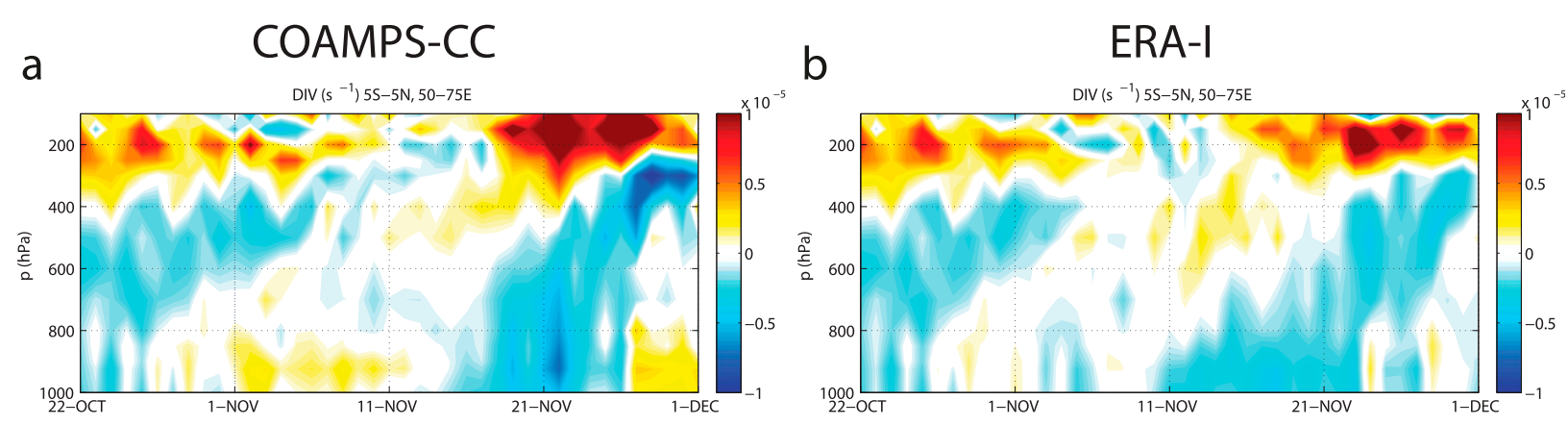

C

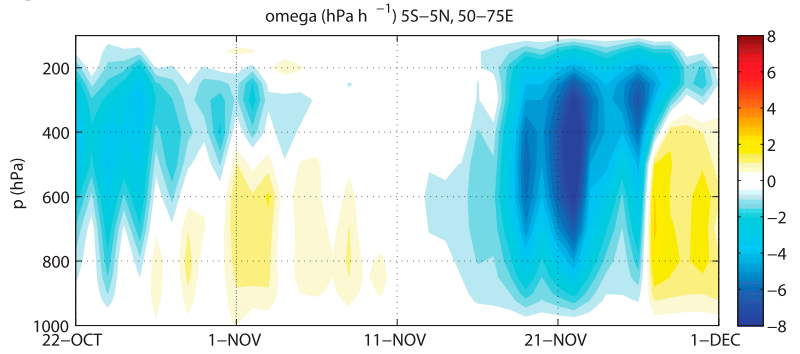

d

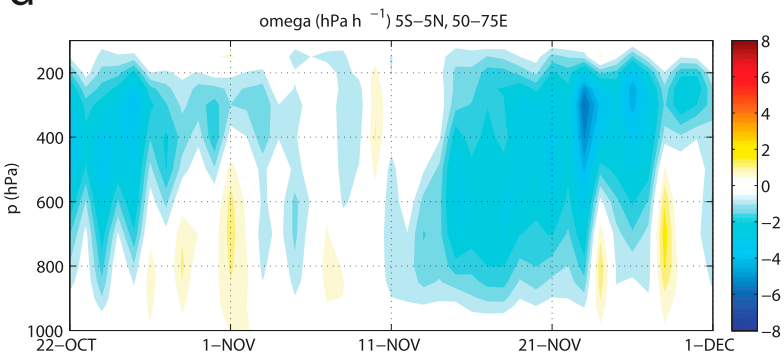

FIG. 15. As in Fig. 14, but for (a),(b) horizontal divergence $\left(\mathrm{s}^{-1}\right)$ and (c),(d) $\omega\left(\mathrm{hPa} \mathrm{h}^{-1}\right)$.

out by drying due to precipitation fallout (Figs. 17a,b). Nonetheless, overall a net moistening tendency remains during the convective build-up phase, evident from 11 to 21 November (Figs. 17c,d). Moistening due to surface evaporation, evaporation of precipitation, and subgrid-scale processes also appear to be quite important to the beginnings of the return to moistening at the low levels during the convectively suppressed

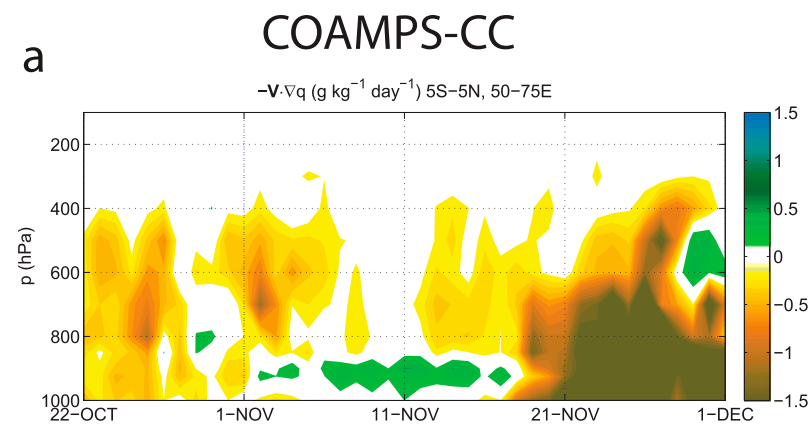

C

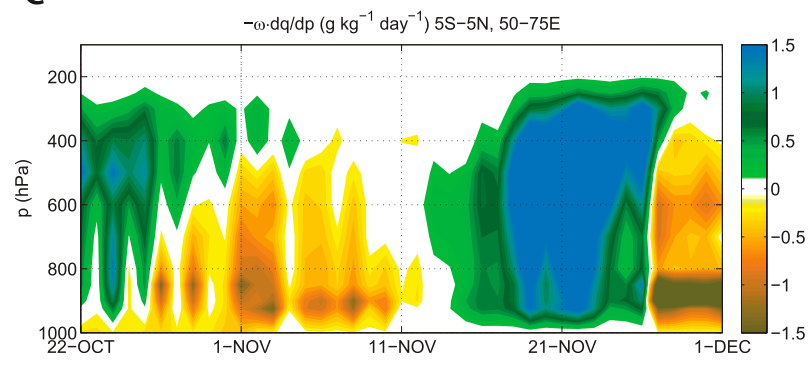

phase (Figs. 17a,b). Capturing the correct timing and vertical level of moistening and drying processes appears to be essential in order for COAMPS to predict MJO2. The fact that COAMPS produces excessive moistening through vertical advection is strongly tied to excessive convection, and is a likely culprit in terms of why the model overpredicts the strength of MJO2. Otherwise, the timing and vertical distribution of

b

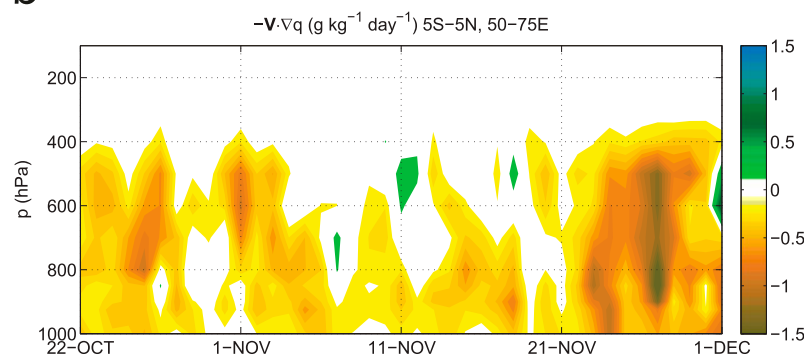

d

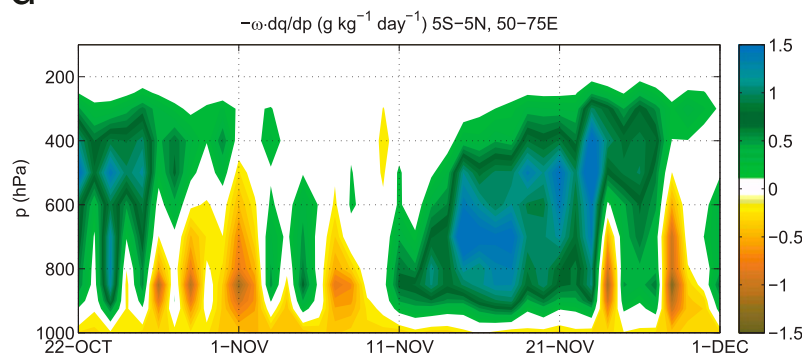

FIG. 16. As in Fig. 14, but for (a),(b) horizontal advection of $q\left(\mathrm{~g} \mathrm{~kg}^{-1} \mathrm{day}^{-1}\right)$ and (c),(d) vertical advection of $q\left(\mathrm{~g} \mathrm{~kg}^{-1} \mathrm{day}^{-1}\right)$. 

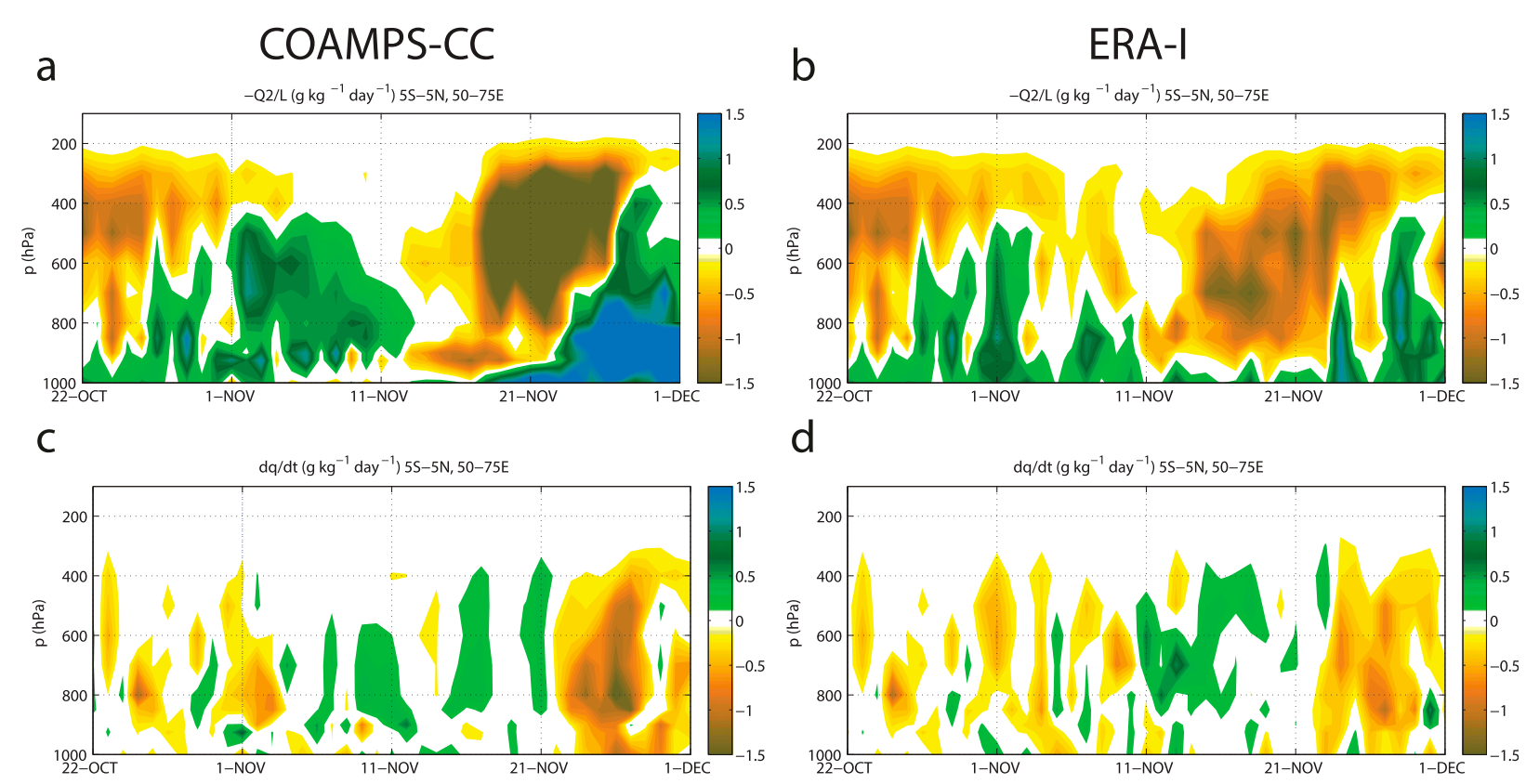

FIG. 17. As in Fig. 14, but for (a),(b) moistening and drying due to condensational and evaporational processes and subgrid-scale moisture flux convergence $\left(\mathrm{g} \mathrm{kg}^{-1} \mathrm{day}^{-1}\right)$ and (c),(d) the total moisture tendency from Eq. (1) $\left(\mathrm{g} \mathrm{kg}^{-1} \mathrm{day}^{-1}\right)$.

the horizontal and vertical advection of moisture in COAMPS is quite realistic.

We have now seen that coupling is extremely important for NAVGEM multiweek forecast skill. In the absence of coupling, the necessary ocean warming fails to occur during the convectively suppressed phase following MJO1. Without this warming, latent heat fluxes are reduced, and the necessary deep convection fails to develop late in the period. However, it remained an open question as to whether or not a coupled COAMPS domain using ICs/BCs from the NAVGEM run that failed to develop $\mathrm{MJO} 2$ would be capable of predicting $\mathrm{MJO} 2$. It appears that November 2011 is a case in which local processes dominate, and regional COAMPS simulations perform skillfully even if NAVGEM is not coupled. For the successive MJO events of November 2011, local processes captured by COAMPS included a westwardpropagating equatorial Rossby wave, rapid SST warming during the convectively suppressed phase following MJO1, and realistic moisture tendencies associated with both MJO events.

\section{November 2013: a nonevent COAMPS simulation}

In the previous section, it was shown that COAMPS can accurately predict the onset and development of an MJO event 20-30 days into the forecast. These findings beg the question: was there any skill in the forecast, or was it just luck? The fact that there was an apparent moist bias and an overprediction of convection suggests that perhaps COAMPS will inevitably trigger too strong an MJO or cyclic MJOs. To address this concern, a forecast for November 2013 was run using NAVGEM analyses as boundary conditions. This period was preceded by weak MJO activity over the Indian Ocean in October, and some additional weak MJO activity in the latter half of November (Fig. 18b). Similar to the forecast for the 2011 event, COAMPS was too moist throughout the troposphere beyond the first 10 days of simulation, especially at the middle levels (Figs. 19a,b). However, unlike in the 2011 event, the predicted vertical advection of moisture is actually lower than ERA-I for most of the period (Figs. 19c,d). These time-pressure cross sections, along with longitude-time Hovmöllers of precipitation rate validated against TRMM (Figs. 18c,d), suggest that there is actually reduced convection in this COAMPS forecast versus reality in the latter half of November.

Early in the forecast, a weak MJO active phase becomes artificially amplified by COAMPS (Figs. 18a,c) before stalling from $90^{\circ}$ to $100^{\circ} \mathrm{E}$ and eventually dissipating. This period of enhanced MJO activity is then followed by a stronger suppressed phase. Unlike in the COAMPS forecast of the 2011 event, which developed very strong anomalous westerlies over the Indian Ocean (Fig. 7) and excessive convection (Fig. 9) in the latter half of the forecast, the forecast for the 2013 event develops strong anomalous easterlies (Fig. 18a) and overall reduced deep convection versus reality (Figs. 18c,d). Therefore, the results are mixed: the current COAMPS 

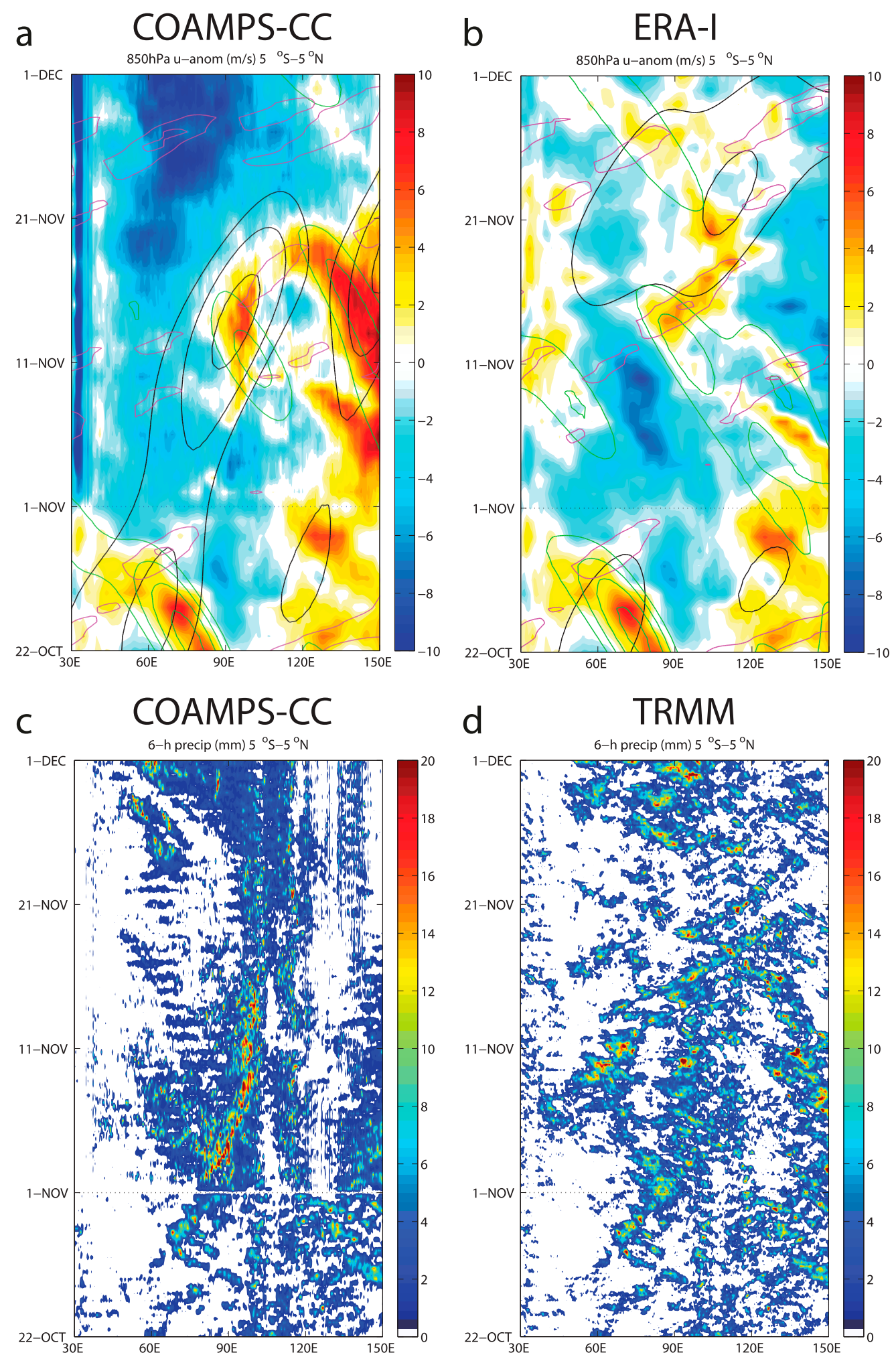

FIG. 18. Hovmöller diagrams of (a),(b) $850 \mathrm{hPa} u$ anomaly ( $\mathrm{m} \mathrm{s}^{-1}$, shaded) and (c),(d) 6-h precipitation (mm, shaded) for November 2013 from $5^{\circ} \mathrm{S}-5^{\circ} \mathrm{N}, 30^{\circ}-150^{\circ} \mathrm{E}$. Included are (a),(c) the COAMPS-CC forecast and (b) ERA-I and (d) TRMM for verification. 

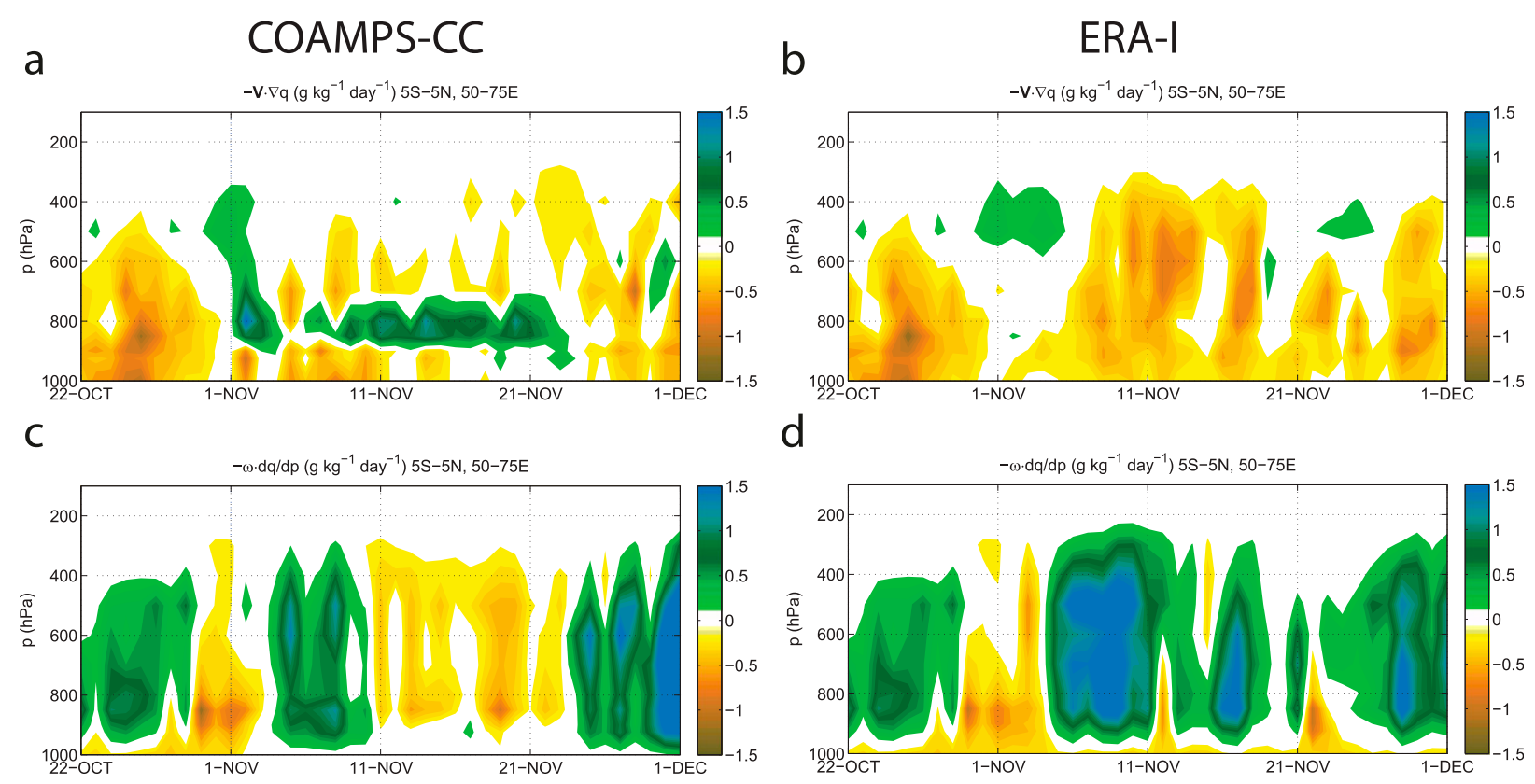

FIG. 19. Time-pressure cross sections of (a),(b) horizontal advection of $q\left(\mathrm{~g} \mathrm{~kg}^{-1} \mathrm{day}^{-1}\right)$ and (c),(d) vertical advection of $q$ (g kg $\left.{ }^{-1} \mathrm{day}^{-1}\right)$ from (a),(c) COAMPS-CC and (b),(d) ERA-I for November 2013 , averaged from $5^{\circ} \mathrm{S}-5^{\circ} \mathrm{N}, 50^{\circ}-75^{\circ} \mathrm{E}$.

wet bias does exaggerate MJO intensity, but not necessarily the cyclic feature within the 30-day timeframe within the forecast. With strong low-level easterlies dominating, there are no indications in the wind field at the end of 30 days that the atmosphere has yet begun to precondition for a cyclic event. It is possible that the slight uptick in precipitation at the end of the integration is indicative of the beginnings of a cyclic event, but without further evidence in the wind fields, the precipitation signal alone is inconclusive. Perhaps future experiments can include longer forecasts to see if a cyclic MJO does eventually develop as a result of the moist bias in the 30-60-day timeframe.

Last, it is also apparent that the forecast from November 2013 is vastly inferior in the timing and propagation of MJO, Rossby, and Kelvin waves versus the November 2011 forecast. This suggests that stronger waves and more pronounced forcing lend to greater predictive skill than weaker waves and poorly defined forcing. A much larger sample of events would be necessary to confirm or deny this hypothesis.

\section{Conclusions}

In this study, a series of experiments were performed in order to assess forecasts from a regional COAMPS system embedded in a global NAVGEM system, and to understand the importance (or lack of importance) of lateral boundary conditions for the skill of the regional system. The ability of various model configurations to reproduce the successive MJO events of November 2011 was tested. In the NAVGEM experiments, sensitivity to the lower boundary condition was explored by varying SST between fixed (NAVGEM-F), observed (NAVGEM-O), and fully coupled to HYCOM (NAVGEM-C). For the COAMPS simulations, sensitivity to the lateral boundary condition was explored by using each of the aforementioned NAVGEM simulations as boundary conditions (COAMPSCF, COAMPS-CO, and COAMPS-CC, respectively). All COAMPS simulations were run fully coupled to NCOM.

All three NAVGEM simulations initialize with a realistic MJO1 from days 1 to 10 . From days 10 to 20, MJO1 slows unrealistically in all three simulations, with the convection having trouble passing east of the Maritime Continent. Overall, the slowing of MJO1 is the greatest in NAVGEM-F. However, the most glaring deficiency with fixed SSTs becomes apparent around day 20, as NAVGEM fails to produce a meaningful MJO2. Coupling to HYCOM produces the best forecast, with the most realistic MJO2 that develops and propagates eastward from days 20 to 30 . Interestingly, using observed SSTs improves the forecast versus fixed SSTs, but still performs worse than the coupled run. This appears to be due to errors in the location of the wind and convection associated with $\mathrm{MJO} 2$, primarily manifesting itself as a slow bias which results in cooling beneath the model's MJO. Errors that originate from a phase shift between the model's convection and the observed SSTs when the models are uncoupled was hypothesized to occur in Ulate et al. (2015). 
In ERA-I, and to a lesser extent the NAVGEM simulations, there is evidence of globally circumnavigating signal in vp200 associated with MJO1 that reemerges over the western Indian Ocean. This area of enhanced upper-level divergence perhaps plays a role in initiating, or the strengthening MJO2. Note that $\mathrm{Li}$ et al. (2015) argue that this upper-level signal did not contribute to the development of $\mathrm{MJO} 2$, since enhanced moistening and ascent were already occurring prior to the reemergence of this wave over the western Indian Ocean around 20 November. However, we would argue that the association between the upper-level signal of MJO1 and the strengthening of $\mathrm{MJO} 2$ is clear, as there is a distinct strengthening of low-level westerly wind and convection associated with $\mathrm{MJO} 2$ around this time. There is no such evidence of a globally circumnavigating signal in either u850 or OLR, as low-level westerly winds and convection associated with the MJO have trouble surviving the cooler Eastern Pacific and crossing South America.

Additionally, a westward-propagating Rossby wave excited by MJO1 around 5 November interacts with MJO2 around 20-25 November. As with the upper-level remnants of MJO1, this Rossby wave also likely contributes to the early development of MJO2. The timing of the development and westward propagation of the Rossby wave is relatively well captured in NAVGEM, although the wave is too weak in all three simulations. As with the two MJO events, the timing, strength, and location of the Rossby wave is most realistic in NAVGEM-C and least realistic in NAVGEM-F.

Next, three COAMPS simulations of the November 2011 event were examined. The key result of this part of the study is that even when initialized from NAVGEM-F, which does not have $\mathrm{MJO} 2$ in the wind or precipitation fields and weaker globally circumnavigating signal in VP, COAMPS still captures the second MJO event. Therefore, it does not appear that capturing processes external to the COAMPS domain are as important in initiating $\mathrm{MJO} 2$ as are processes internal to COAMPS domain, over the Indian Ocean region. This case appears to be an exception to Matthews's (2008) finding that the globally circumnavigating signal is the dynamical link between a precursor and successive MJO event. Ocean coupling undeniably adds skill to the 30-day NAVGEM forecasts. The fact that ocean cooling below MJO1 and warming during the suppressed activity period were well represented in the COAMPS-NCOM system no doubt contributes to the ability of COAMPS to initiate MJO2 in the right place at the right time.

There are several key processes that are identified that contribute to the development of MJO2. In the wake of MJO1, a significant lack of cloud cover results in increased shortwave warming, while reduced surface wind leads to a period of reduced latent cooling. These factors result in anomalous ocean warming of $1^{\circ}-1.5^{\circ} \mathrm{C}$, which contributes to the development of widespread deep convection around 23 November per TRMM, or several days earlier in COAMPS. MJO1 also triggers a westward-propagating Rossby wave that intersects this region of deep convection associated with $\mathrm{MJO} 2$ from 25 November through 1 December. This Rossby wave enhances low-level westerly winds, increasing latent heat fluxes through increased evaporation. $\mathrm{Li}$ et al. (2015) also attribute the period of increased fluxes associated with anomalous easterly flow 1 week earlier to this Rossby wave. Additionally, we find that this Rossby wave is associated with a region of negative VP anomalies, which favors enhanced vertical motion and the generation of precipitation. The interaction between the Rossby wave and $\mathrm{MJO} 2$ appears to be well-resolved in COAMPS, and, combined with an accurate prediction of the timing and location of deep convection, likely leads to a reasonable development of $\mathrm{MJO} 2$ and its associated westerly wind burst.

While COAMPS accurately predicted the timing and location of $\mathrm{MJO} 2$, the model has a significant strong bias evident in both dynamic and thermodynamic fields. It was found that excessive ocean warming during the inactive phase between MJO events likely contributed to excessive latent heat flux as MJO2 amplified, as was the case in the 45-km COAMPS simulations of Hong et al. (2017). The effect of the excessively warm SSTs on the sensible heat flux was comparatively small. Additionally, excessive moistening through vertical motion, along with a general moist bias throughout the lower to middle troposphere, appear to be related to an overall bias of having too much convection during the onset of MJO2. Sudden drying near the end of the simulation from 25 November through 1 December demonstrates that this convection, along with horizontal transport from off-equatorial latitudes, does ultimately remove the excess moisture from the column.

Overall, vertical advection of moisture appears to dominate the column moistening tendency associated with the onset of MJO2, which is largely consistent with Sobel et al. (2014). However, much of this moistening is negated due to drying associated with condensational processes and the generation of precipitation. Moistening due to evaporation and subgrid-scale processes also appears to contribute to the regime shift from the convectively suppressed phase to the beginnings of a buildup of moisture at the low levels. While $\mathrm{Li}$ et al. (2015) find the zonal advection of moisture to be the primary moisture source in the development of MJO2, we find the net horizontal moisture flux to actually be associated with drying during the onset of $\mathrm{MJO} 2$ due to 
the meridional advection of dry air. Much of this discrepancy is due to the fact that our domain for averaging extends much farther east than does the domain of Li et al. (2015). Horizontal and vertical moisture advection in these COAMPS simulations was found to be largely consistent with ERA-I.

Last, a separate COAMPS simulation of November 2013 was run to address the moist bias and whether or not it will inevitably result in excessive convection that ultimately produces cyclic MJO events. This case was selected as it was only associated with very weak MJO activity as per reanalysis. The results were mixed, as COAMPS persists and even strengthens some MJO activity over the Indian Ocean that began in October, which verification shows to have fallen apart much more quickly. Similar to the November 2011 simulations, COAMPS is much too moist at the lower to midlevels. However, unlike the 2011 case, excessive vertical moisture advection does not develop, nor does a second MJO form near the end of the simulation. It is possible that a second MJO could have formed beyond the 30-day forecast for the November 2013 event, but there are no indications in the wind fields (a slight uptick in precipitation at the end of the simulation notwithstanding) at the end of 30 days that the atmosphere has even begun to precondition for a cyclic event. Therefore, we can conclude with reasonable confidence that the ability of COAMPS to capture the second MJO event in November 2011 was the result of real multiweek sources of predictability, including slowly varying phenomenon such as SST warming and Rossby wave interaction, and not simply due to model biases or overactive convection.

Overall, these simulations suggest that both the global NAVGEM and COAMPS regional models can predict MJO activity out to at least 30 days when coupled to an ocean model. This study also demonstrates that a coupled regional COAMPS forecast can perform quite well locally, even when using the computationally inexpensive NAVGEM simulations with fixed SST for lateral boundary conditions. The ability of COAMPS to adequately represent local phenomena, such as a slowly evolving Rossby wave, SST warming during the convectively suppressed phase between MJO events, and a realistic vertical and temporal structure of the moisture tendency terms, all contribute to a skillful multiweek MJO forecast. In a future study, we seek to examine longer forecasts out to 60 days and include additional cases in order to understand limiting factors in the predictability of the MJO.

Acknowledgments. We acknowledge the support of the Chief of Naval Research through the NRL Base
Program and ONR programs, PE 0601153N and PE $0602435 \mathrm{~N}$. We thank two anonymous reviewers for their constructive comments, which have helped us to improve the manuscript significantly.

\section{REFERENCES}

Allard, R. A., and Coauthors, 2010: Validation test report for the Coupled Ocean/Atmosphere Mesoscale Prediction System (COAMPS) version 5. Naval Research Laboratory Rep. NRL/ MR/7320-10-9283, 172 pp.

Bellenger, H., and J. P. Duvel, 2009: An analysis of tropical ocean diurnal warm layers. J. Climate, 22, 3629-3646, https://doi.org/ 10.1175/2008JCLI2598.1.

Bleck, R., 2002: An oceanic general circulation model framed in hybrid isopycnic-Cartesian coordinates. Ocean Modell., 4, 5588, https://doi.org/10.1016/S1463-5003(01)00012-9.

Chen, S., and Coauthors, 2003: COAMPS version 3 model description: General theory and equations. Naval Research Laboratory Tech. Rep. NRL/PU7500-04-448, 141 pp.

—- and Coauthors, 2015: A study of CINDY/DYNAMO MJO suppressed phase. J. Atmos. Sci., 72, 3755-3779, https:// doi.org/10.1175/JAS-D-13-0348.1.

Dee, D. P., and Coauthors, 2011: The ERA-interim reanalysis: Configuration and performance of the data assimilation system. Quart. J. Roy. Meteor. Soc., 137, 553-597, https://doi.org/ 10.1002/qj.828.

DeMott, C. A., N. P. Klingaman, and S. J. Woolnough, 2015: Atmosphere-ocean coupled processes in the Madden-Julian oscillation. Rev. Geophys., 53, 1099-1154, https://doi.org/ 10.1002/2014RG000478.

Fu, Q., and K. N. Liou, 1993: Parameterization of the radiative properties of cirrus clouds. J. Atmos. Sci., 50, 2008-2025, https://doi.org/10.1175/1520-0469(1993)050<2008:POTRPO> 2.0.CO;2.

Fu, X., W. Wang, J.-Y. Lee, B. Wang, K. Kikuchi, J. Xu, J. Li, and S. Weaver, 2015: Distinctive roles of air-sea coupling on different MJO events: A new perspective revealed from the DYNAMO/CINDY field campaign. Mon. Wea. Rev., 143, 794-812, https://doi.org/10.1175/MWR-D-14-00221.1.

Guo, Y., D. E. Waliser, and X. Jiang, 2015: A systematic relationship between the representations of convectively coupled equatorial wave activity and the Madden-Julian oscillation in climate model simulations. J. Climate, 28, 1881-1904, https://doi.org/10.1175/JCLI-D-14-00485.1.

Haltiner, G. J., and R. T. Williams, 1980: Numerical Prediction and Dynamic Meteorology. John Wiley and Sons, 477 pp.

Hodur, R. M., 1997: The Naval Research Laboratory's Coupled Ocean/Atmospheric Mesoscale Prediction System (COAMPS). Mon. Wea. Rev., 125, 1414-1430, https://doi.org/10.1175/ 1520-0493(1997)125<1414:TNRLSC >2.0.CO;2.

Hogan, T. F., and Coauthors, 2014: The navy global environmental model. Oceanography, 27, 116-125, https://doi.org/10.5670/ oceanog.2014.73.

Hong, X., S. Wang, T. R. Holt, P. J. Martin, and L. O’Neill, 2013: Modulation of the sea-surface temperature in the Southeast Pacific by the atmospheric low-level coastal jet. J. Geophys. Res. Oceans, 118, 3979-3998, https://doi.org/ 10.1002/jgrc.20289.

— C. Reynolds, J. Doyle, P. May, and L. O'Neill, 2017: Assessment of upper-ocean variability and the Madden-Julian Oscillation in extended-range air-ocean coupled mesoscale 
simulations. Dyn. Atmos. Oceans, 78, 89-105, https://doi.org/ 10.1016/j.dynatmoce.2017.03.002.

Hsu, P.-C., and T. Li, 2012: Role of the boundary layer moisture asymmetry in causing the eastward propagation of the Madden-Julian oscillation. J. Climate, 25, 4914-4931, https:// doi.org/10.1175/JCLI-D-11-00310.1.

Huffman, G. J., and Coauthors, 2007: The TRMM Multisatellite Precipitation Analysis (TMPA): Quasi-global, multiyear, combined-sensor precipitation estimates at fine scales. J. Hydrometeor., 8, 38-55, https://doi.org/10.1175/JHM560.1.

Hung, C., and C. Sui, 2018: A diagnostic study of the evolution of the MJO from Indian Ocean to Maritime Continent: Wave dynamics versus advective moistening processes. J. Climate, 31, 4095-4115, https://doi.org/10.1175/JCLI-D-17-0139.1.

Hunke, E. C., and W. H. Lipscomb, 2010: CICE: The Los Alamos Sea Ice Model documentation and software user's manual version 4.1. Doc. LA-CC-06-012, 76 pp., http://csdms.colorado.edu/w/ images/CICE_documentation_and_software_user's_manual.pdf.

Janiga, M. A., and C. Zhang, 2016: MJO moisture budget during DYNAMO in a cloud-resolving model. J. Atmos. Sci., 73, 2257-2278, https://doi.org/10.1175/JAS-D-14-0379.1.

—, C. J. Schreck, J. A. Ridout, M. Flatau, N. P. Barton, E. J. Metzger, and C. A. Reynolds, 2018: Subseasonal forecasts of convectively coupled equatorial waves and the MJO: Activity and predictive skill. Mon. Wea. Rev., 146, 2337-2360, https:// doi.org/10.1175/MWR-D-17-0261.1.

Kiladis, G. N., M. C. Wheeler, P. T. Haertel, K. H. Straub, and P. E. Roundy, 2009: Convectively coupled equatorial waves. Rev. Geophys., 47, RG2003, https://doi.org/10.1029/2008RG000266.

Klemp, J., and R. Wilhelmson, 1978: The simulation of threedimensional convective storm dynamics. J. Atmos. Sci., 35, 1070-1096, https://doi.org/10.1175/1520-0469(1978)035<1070: TSOTDC $>2.0 . \mathrm{CO} ; 2$.

Klotzbach, P. J., 2010: On the Madden-Julian oscillation-Atlantic hurricane relationship. J. Climate, 23, 282-293, https://doi.org/ 10.1175/2009JCLI2978.1.

_ 2014: The Madden-Julian oscillation's impacts on worldwide tropical cyclone activity. J. Climate, 27, 2317-2330, https:// doi.org/10.1175/JCLI-D-13-00483.1.

Lee, H.-T., 2014: Climate Algorithm Theoretical Basis Document (C-ATBD): Outgoing Longwave Radiation (OLR)-Daily. NOAA's Climate Data Record (CDR) Program. CDRPATBD-0526, 46 pp., http://www1.ncdc.noaa.gov/pub/data/ sds/cdr/CDRs/Outgoing\%20Longwave \%20Radiation \%20-\% 20Daily/AlgorithmDescription.pdf.

Li, T., C. Zhao, P. C. Hsu, and T. Nasuno, 2015: MJO initiation processes over the tropical Indian Ocean during DYNAMO/ CINDY2011. J. Climate, 28, 2121-2135, https://doi.org/ 10.1175/JCLI-D-14-00328.1.

Lin, Y.-L., R. D. Farley, and H. D. Orville, 1983: Bulk parameterization of the snow field in a cloud model. J. Climate Appl. Meteor., 22, 1065-1092, https://doi.org/10.1175/15200450(1983)022<1065:BPOTSF > 2.0.CO;2.

Liu, M., J. E. Nachamkin, and D. L. Westphal, 2009: On the improvement of COAMPS weather forecasts using an advanced radiative transfer model. Wea. Forecasting, 24, 286-306, https://doi.org/10.1175/2008WAF2222137.1.

Louis, J. F., M. Tiedtke, and J. F. Geleyn, 1982: A short history of the operational PBL parameterization at ECMWF. Proc. ECMWF Workshop on Planetary Boundary Layer Parameterizations, Reading, United Kingdom, ECMWF, 59-79.

MacRitchie, K., and P. E. Roundy, 2012: Potential vorticity accumulation following atmospheric Kelvin waves in the active convective region of the MJO. J. Atmos. Sci., 69, 908-914, https://doi.org/10.1175/JAS-D-11-0231.1.

Madden, R. A., and P. R. Julian, 1971: Detection of a 40-50 day oscillation in the zonal wind in the tropical Pacific. J. Atmos. Sci., 28, 702-708, https://doi.org/10.1175/1520-0469(1971) 028<0702:DOADOI $>2.0$.CO;2.

— in the Tropics with a 40-50 day period. J. Atmos. Sci., 29, 1109-1123, https://doi.org/10.1175/1520-0469(1972)029<1109: DOGSCC $>2.0 . \mathrm{CO} ; 2$.

Martin, P. J., 2000: Description of the Navy Coastal Ocean Model version 1.0. NRL Rep. NRL/FR/7322/00/9962, 45 pp. [Available from NRL, Code 7322, Bldg. 1009, Stennis Space Center, MS 39529-5004.]

Matthews, A. J., 2008: Primary and successive events in the Madden-Julian oscillation. Quart. J. Roy. Meteor. Soc., 134, 439-453, https://doi.org/10.1002/qj.224.

Mellor, G. L., and T. Yamada, 1982: Development of a turbulence closure for geophysical fluid problems. Rev. Geophys. Space Phys., 20, 851-875, https://doi.org/10.1029/ RG020i004p00851.

Molinari, J., K. Lombardo, and D. Vollaro, 2007: Tropical cyclogenesis within an equatorial Rossby wave packet. J. Atmos. Sci., 64, 1301-1317, https://doi.org/10.1175/JAS3902.1.

Pan, H.-L., and W.-S. Wu, 1995: Implementing a mass flux convective parameterization package for the NMC medium-range forecast model. NMC Office Note 409, NOAA, 40 pp., https:// repository.library.noaa.gov/view/noaa/11429.

Reynolds, C. A., J. D. Doyle, and X. Hong, 2016: Examining tropical cyclone-Kelvin wave interactions using adjoint diagnostics. Mon. Wea. Rev., 144, 4421-4439, https://doi.org/ 10.1175/MWR-D-16-0174.1.

Ridout, J. A., Y. Jin, and C.-S. Liou, 2005: A cloud-base quasibalance constraint for parameterized convection: Application to the Kain-Fritsch cumulus scheme. Mon. Wea. Rev., 133, 3315-3334, https://doi.org/10.1175/MWR3034.1.

Rutledge, S. A., and P. V. Hobbs, 1983: The mesoscale and microscale structure and organization of clouds and precipitation in midlatitude cyclones. VIII: A model for the "seederfeeder" process in warm-frontal rainbands. J. Atmos. Sci., 40, 1185-1206, https://doi.org/10.1175/1520-0469(1983)040<1185: TMAMSA $>2.0 . \mathrm{CO} ; 2$.

Shinoda, T., and H. H. Hendon, 1998: Mixed layer modeling of intraseasonal variability in the tropical western Pacific and Indian Oceans. J. Climate, 11, 2668-2685, https://doi.org/ 10.1175/1520-0442(1998)011<2668:MLMOIV>2.0.CO;2.

Sobel, A., S. G. Wang, and D. Kim, 2014: Moist static energy budget of the MJO during DYNAMO. J. Atmos. Sci., 71, 4276-4291, https://doi.org/10.1175/JAS-D-14-0052.1.

Stephens, G. L., P. J. Webster, R. H. Johnson, R. Engelen, and T. L'Ecuyer, 2004: Observational evidence for the mutual regulation of the tropical hydrological cycle and tropical sea surface temperatures. J. Climate, 17, 2213-2224, https://doi.org/ 10.1175/1520-0442(2004)017<2213:OEFTMR>2.0.CO;2.

Sušelj, K., J. Teixeira, and G. Matheou, 2012: Eddy diffusivity/mass flux and shallow cumulus boundary layer: An updraft PDF mulitple mass flux scheme. J. Atmos. Sci., 69, 1513-1533, https://doi.org/10.1175/JAS-D-11-090.1.

Tseng, K. C., C. H. Sui, and T. Li, 2015: Moistening processes for Madden-Julian oscillations during DYNAMO/CINDY. J. Climate, 28, 3041-3057, https://doi.org/10.1175/JCLI-D-14-00416.1.

Ulate, M., C. Zhang, and J. Dudhia, 2015: Role of water vapor and convection-circulation decoupling in MJO simulations by a 
tropical channel model. J. Adv. Model. Earth Syst., 7, 692-711, https://doi.org/10.1002/2014MS000393.

Ventrice, M. J., M. C. Wheeler, H. H. Hendon, C. J. Schreck III, C. D. Thorncroft, and G. N. Kiladis, 2013: A modified multivariate Madden-Julian oscillation index using velocity potential. Mon. Wea. Rev., 141, 4197-4210, https://doi.org/ 10.1175/MWR-D-12-00327.1.

Weller, R. A., and S. P. Anderson, 1996: Surface meteorology and air-sea fluxes in the western equatorial Pacific warm pool during the TOGA Coupled Ocean-Atmosphere Response Experiment. J. Climate, 9, 1959-1990, https://doi.org/10.1175/ 1520-0442(1996)009<1959:SMAASF $>2.0 . C O ; 2$.

Xiang, B., M. Zhao, X. Jiang, S.-J. Lin, T. Li, X. Fu, and G. Vecchi, 2015: The 3-4 week MJO prediction skill in a
GFDL coupled model. J. Climate, 28, 5351-5364, https:// doi.org/10.1175/JCLI-D-15-0102.1.

Zhang, C., 2005: Madden-Julian Oscillation. Rev. Geophys., 43, RG2003, https://doi.org/10.1029/2004RG000158.

- 2013: Madden-Julian oscillation: Bridging weather and climate. Bull. Amer. Meteor. Soc., 94, 1849-1870, https://doi.org/ 10.1175/BAMS-D-12-00026.1.

_ , and J. Ling, 2012: Potential vorticity of the Madden-Julian oscillation. J. Atmos. Sci., 69, 65-78, https://doi.org/10.1175/ JAS-D-11-081.1.

Zhao, Q., and F. H. Carr, 1997: A prognostic cloud scheme for operational NWP models. Mon. Wea. Rev., 125, 1931-1953, https://doi.org/10.1175/1520-0493(1997)125<1931:APCSFO> 2.0.CO;2. 